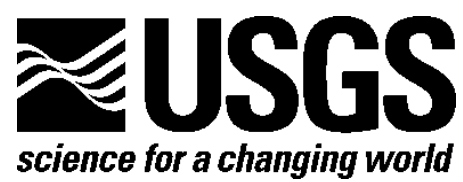

Prepared in cooperation with the U.S. Fish and Wildlife Service, Region 8

\title{
Improve Wildlife Species Tracking_Implementing an Enhanced Global Positioning System Data Management System for California Condors
}

By Robert G. Waltermire, Christopher U. Emmerich, Laura C. Mendenhall, Gil Bohrer, Rolf P. Weinzierl, Andrew J. McGann, Pat K. Lineback, Tim J. Kern, and David C. Douglas

Open-File Report 2016-1030

U.S. Department of the Interior

U.S. Geological Survey 


\section{U.S. Department of the Interior \\ SALLY JEWELL, Secretary}

\section{U.S. Geological Survey \\ Suzette M. Kimball, Director}

For more information on the USGS-the Federal source for science about the Earth,

its natural and living resources, natural hazards, and the environment-visit

http://www.usgs.gov/ or call 1-888-ASK-USGS (1-888-275-8747).

For an overview of USGS information products, including maps, imagery, and publications, visit http://store.usgs.gov/.

Any use of trade, firm, or product names is for descriptive purposes only and does not imply endorsement by the U.S. Government.

Although this information product, for the most part, is in the public domain, it also may contain copyrighted materials as noted in the text. Permission to reproduce copyrighted items must be secured from the copyright owner.

Suggested Citation:

Waltermire, R.G., Emmerich, C.U., Mendenhall, L.C., Bohrer, Gil, Weinzierl, R.P., McGann, A.J., Lineback, P.K., Kern, T.J., and Douglas, D.C., 2016, Improve wildlife species tracking—Implementing an enhanced global positioning system data management system for California condors: U.S. Geological Survey Open-File Report 2016-1030, 46 p., http://dx.doi.org/10.3133/ofr20161030.

ISSN 2331-1258 (online) 


\section{Contents}

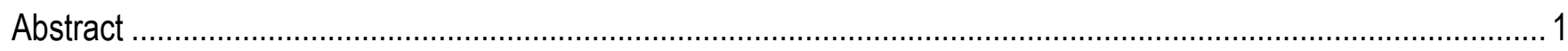

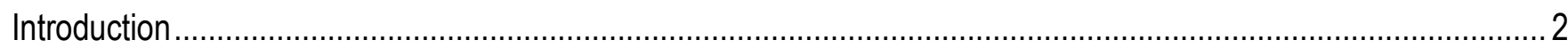

Objective 1-Streaming Global Positioning System Data into Movebank ...................................................... 6

Objective 2-Associating Transmitter-Identifier with Condor-Identifier ...........................................................

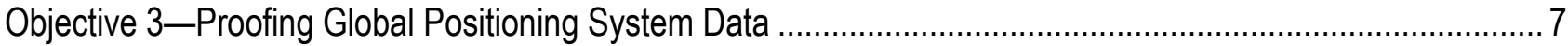

Objective 4-Associating Environmental Data with Global Positioning System Tracking Data ...........................7

Objective 5-Moving Data from Movebank to ScienceBase for Archive ......................................................... 7

Objective 6-Automating the Daily Map ……......................................................................................

Objective 7-Automating Alerts Indicating Transmitter Readiness and Condor Behavior .................................. 7

Objective 8-Managing Legacy and Current Data ............................................................................... 8

Objective 9-Testing the Functionality of Global Positioning System Transmitters ......................................... 8

Objective 10-Developing and Deploying Geofence Capability ................................................................. 8

Objective 11-Enhancing the Douglas-Argos-Filter ……………......................................................... 8

Objective 12-Consolidating Condor Profiles with the Tracking Database ................................................ 9

Objective 13-Including Condor Tracking Data in ServCat .......................................................................

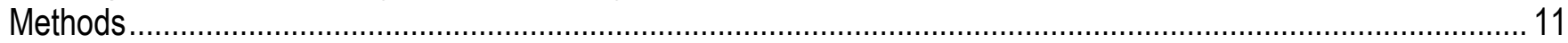

Design, Testing, and Evolution of Prototype Transmitters from Cellular Tracking Technologies, LLC ${ }^{\text {TM }}$............... 13

Objective 1-Streaming Global Positioning System Data into Movebank ...................................................... 16

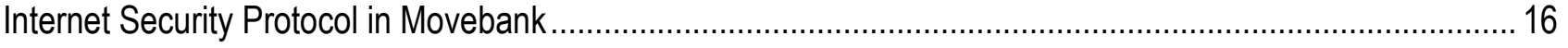

Objective 2-Associating Transmitter-Identifier with Condor-Identifier ...................................................... 16

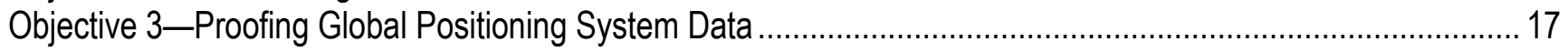

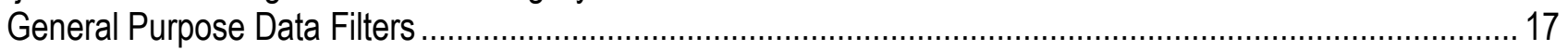

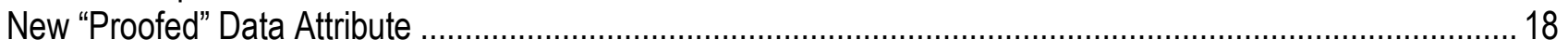

Objective 4-Associating Environmental Data with Global Positioning System Tracking Data............................ 18

Objective 5-Moving Data from Movebank to ScienceBase for Archive ....................................................... 19

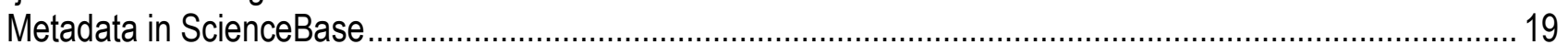

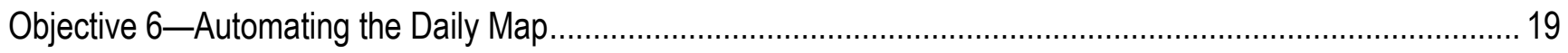

Visualization and Symbology....................................................................................................... 20

Objective 7-Automating Alerts Indicating Transmitter Readiness and Condor Behavior ...................................2 21

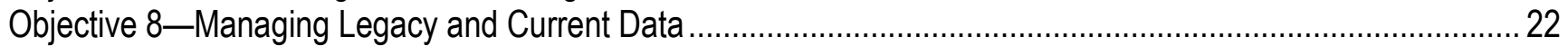

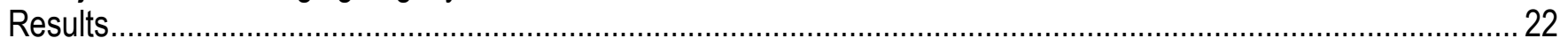

Objective 1-Streaming Global Positioning System Data into Movebank ....................................................... 22

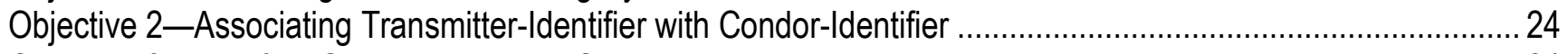

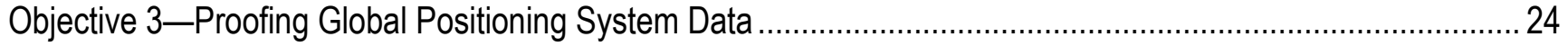

Objective 4-Associating Environmental Data with Global Positioning System Tracking Data............................. 24

Objective 5-Moving Data from Movebank to ScienceBase for Archive .........................................................2 26

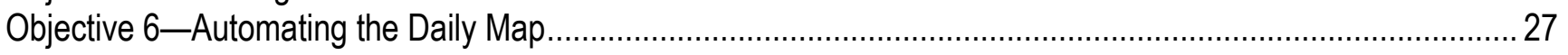

Objective 7-Automating Alerts Indicating Transmitter Readiness and Condor Behavior ..................................2 27

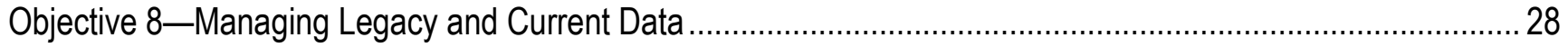

Accessing California Condor Project Data in ScienceBase ........................................................................... 29

Global Positioning System Data Source Naming Conventions.................................................................2 29

Global Positioning System Project Naming Conventions …………….....................................................2 29

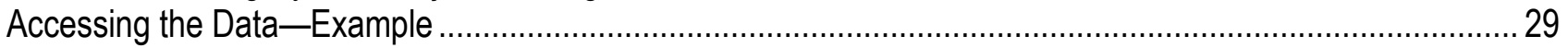




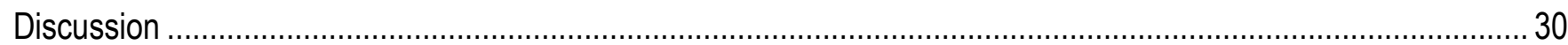

Utility of the System for Other Wildlife Tracking Efforts ......................................................................... 30

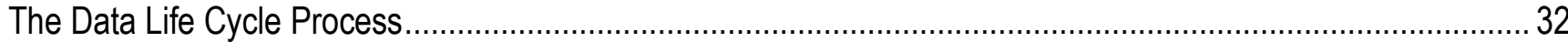

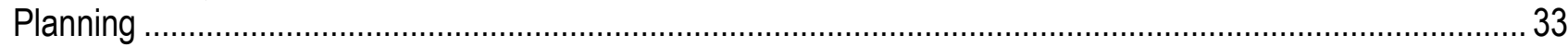

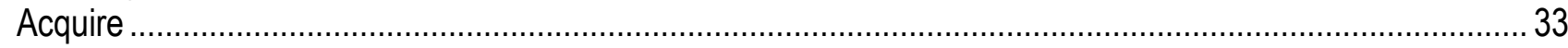

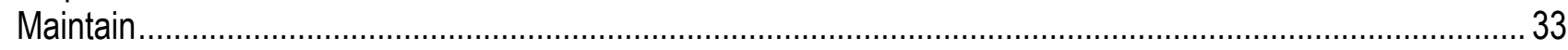

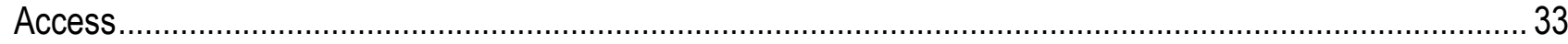

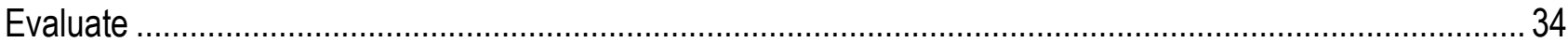

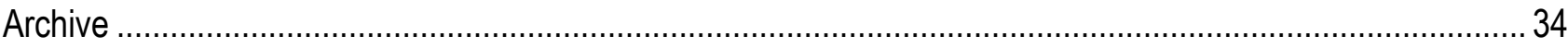

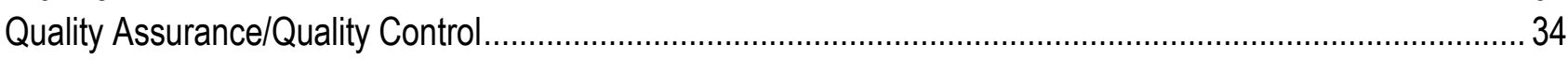

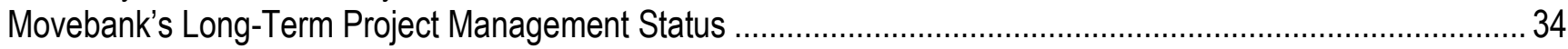

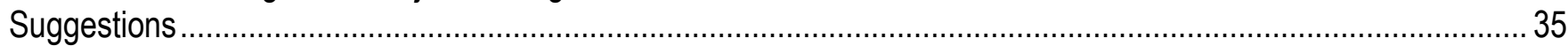

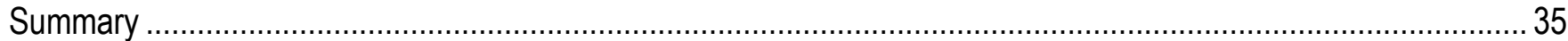

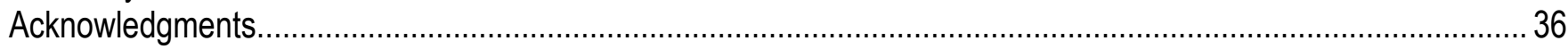

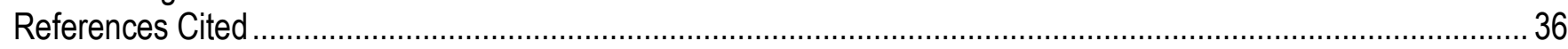

Appendix 1. Project Contributors Present at the December 17-18, 2013, Project Planning Meeting in Ventura,

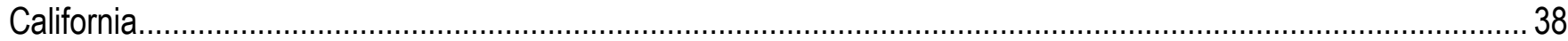

Appendix 2. Table of Specifications for Global Positioning System Transmitters Deployed on California Condors. . 40

Appendix 3. California Condor Management and Analysis Portal (CCMAP) ...................................................... 43

Appendix 4. Long-Term Commitment by the Max Planck Institute for Ornithology to Operate Movebank................ 46

\section{Figures}

1. California condor with a Platform Transmitter Terminal-100 50-gram solar patagial Argos/global positioning system from Microwave Telemetry, Inc. ${ }^{\mathrm{TM}}$

2. Initial U.S. Fish and Wildlife Service, Pinnacles National Park, and Ventana Wildlife Society global positioning system data workflow

3. Implemented global positioning system (GPS) data capture and delivery system for managing populations of the California condor .....

4. Study area showing approximate California condor range for both the central and southern populations... 12

5. A top-down view of Cellular Tracking Technologies, LLC ${ }^{\text {TM }}$ prototype number 1 with solar panel and

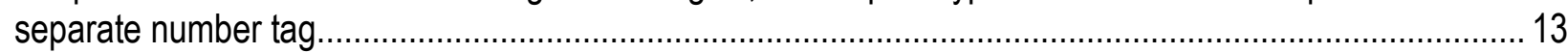

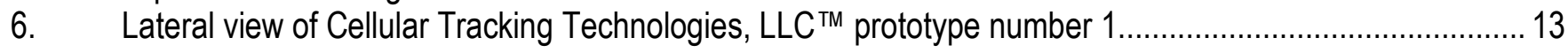

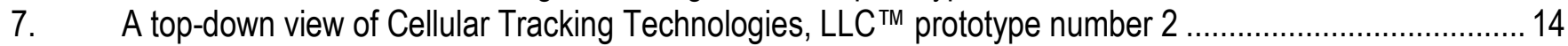

8. Lateral view of Cellular Tracking Technologies, LLC ${ }^{\text {TM }}$ prototype number 2 …....................................... 14

9. The final Cellular Tracking Technologies, LLC ${ }^{\text {TM }}$ transmitter design shown mounted on the patagium

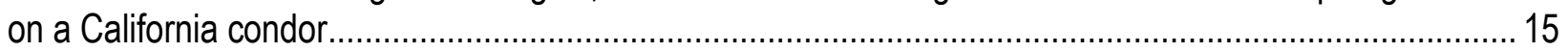

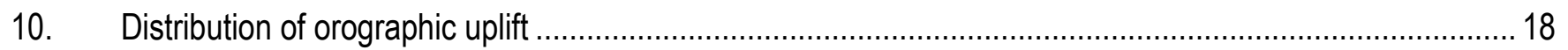

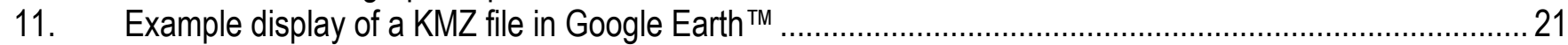

12. A Movebank data interface map showing a sample of California condor track locations.......................... 25

13. An example of the Movebank Environmental Data Automated Track Annotation System (Env-DATA) visualization tool illustrating Galapagos Albatross data annotated with tailwind speed ............................... 26

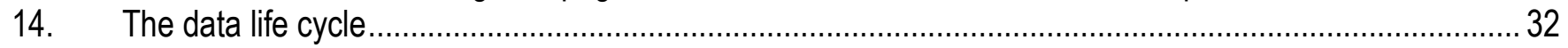




\section{Tables}

1. The cost comparison (2014) of three wildlife tracking global positioning system data providers ................2 23

2-1. Specification for Global Positioning System Transmitters Deployed on California Condors.

\section{Conversion Factors}

Inch/Pound to International System of Units

\begin{tabular}{lcl}
\hline \multicolumn{1}{c}{ Multiply } & \multicolumn{1}{c}{ By } & \multicolumn{1}{c}{ To obtain } \\
\hline inch (in.) & \multicolumn{1}{c}{ Length } & \\
inch (in.) & 2.54 & centimeter $(\mathrm{cm})$ \\
foot (ft) & 25.4 & millimeter $(\mathrm{mm})$ \\
mile (mi) & 0.3048 & meter $(\mathrm{m})$ \\
mile, nautical (nmi) & 1.609 & kilometer $(\mathrm{km})$ \\
yard (yd) & 1.852 & kilometer $(\mathrm{km})$ \\
\hline
\end{tabular}

Temperature in degrees Celsius $\left({ }^{\circ} \mathrm{C}\right)$ may be converted to degrees Fahrenheit $\left({ }^{\circ} \mathrm{F}\right)$ as ${ }^{\circ} \mathrm{F}=\left(1.8 \times{ }^{\circ} \mathrm{C}\right)+32$.

Temperature in degrees Fahrenheit $\left({ }^{\circ} \mathrm{F}\right)$ may be converted to degrees Celsius $\left({ }^{\circ} \mathrm{C}\right)$ as ${ }^{\circ} \mathrm{C}=\left({ }^{\circ} \mathrm{F}-32\right) / 1.8$.

\section{Abbreviations}

API application program interface

CCMAP California Condor Management and Analysis Portal

CESU Cooperative Ecosystem Studies Unit

$\mathrm{CLS}^{\mathrm{TM}} \quad$ Collecte Localisation Satellites

Complex Hopper Mountain National Wildlife Refuge Complex

CSV comma-separated values

CTT Cellular Tracking Technologies, LLC ${ }^{\text {TM }}$

DAF Douglas-Argos-Filter

ECMWF European Centre for Medium-Range Weather Forecasts

ECOS Environmental Conservation Online System

Env-DATA Environmental Data Automated Track Annotation System

Esri Environmental Systems Research Institute

FISMA Federal Information Security Management Act of 2002

FOIA Freedom of Information Act

GIS geographical information system 


\begin{tabular}{|c|c|}
\hline GME & Geospatial Modelling Environment \\
\hline GPS & global positioning system \\
\hline GSM & Global System for Mobile Communication \\
\hline GUI & graphical user interface \\
\hline HDOP & horizontal dilution of precision \\
\hline ID & identifier \\
\hline KML & keyhole markup language \\
\hline KMZ & zipped keyhole markup language file \\
\hline LC MAP & Landscape Conservation Management and Analysis Portal \\
\hline MPIO & Max Planck Institute for Ornithology \\
\hline MTI & Microwave Telemetry, Inc. ${ }^{\mathrm{TM}}$ \\
\hline NARR & North American Regional Reanalysis \\
\hline NPS & National Park Service \\
\hline OTA & over-the-air \\
\hline pinn & Pinnacles National Park Project \\
\hline PTT & Platform Transmitter Terminal \\
\hline ScienceBase & The U.S. Geological Survey Core Science Analytics, Synthesis, and Libraries ScienceBase Projec \\
\hline sCal & Southern California U.S. Fish and Wildlife Service Project \\
\hline SSL & Secure Sockets Layer \\
\hline SSP & Science Support Partnership \\
\hline System & Global Positioning System Data Capture, Delivery, and Archive System \\
\hline TLS & Transport Layer Security \\
\hline UHF & ultra high frequency \\
\hline USFWS & U.S. Fish and Wildlife Service \\
\hline USGS & U.S. Geological Survey \\
\hline VDOP & vertical dilution of precision \\
\hline VHF & very high frequency \\
\hline VWS & Ventana Wildlife Society \\
\hline vws & Ventana Wildlife Society Project \\
\hline WMS & Web Map Service \\
\hline
\end{tabular}




\title{
Improve Wildlife Species Tracking-Implementing an Enhanced Global Positioning System Data Management System for California Condors
}

\author{
By Robert G. Waltermire, ${ }^{1}$ Christopher U. Emmerich, ${ }^{2}$ Laura C. Mendenhall, ${ }^{3}$ Gil Bohrer, ${ }^{4}$ Rolf P. Weinzierl, ${ }^{5}$ \\ Andrew J. McGann, ${ }^{6}$ Pat K. Lineback, ${ }^{3}$ Tim J. Kern, ${ }^{1}$ and David C. Douglas ${ }^{1}$
}

\begin{abstract}
U.S. Fish and Wildlife Service (USFWS) staff in the Pacific Southwest Region and at the Hopper Mountain National Wildlife Refuge Complex requested technical assistance to improve their global positioning system (GPS) data acquisition, management, and archive in support of the California Condor Recovery Program. The USFWS deployed and maintained GPS units on individual Gymnogyps californianus (California condor) in support of long-term research and daily operational monitoring and management of California condors. The U.S. Geological Survey (USGS) obtained funding through the Science Support Program to provide coordination among project participants, provide GPS Global System for Mobile Communication (GSM) transmitters for testing, and compare GSM/GPS with existing Argos satellite GPS technology. The USFWS staff worked with private companies to design, develop, and fit condors with GSM/GPS transmitters. The Movebank organization, an online database of animal tracking data, coordinated with each of these companies to automatically stream their GPS data into Movebank servers and coordinated with USFWS to improve Movebank software for managing transmitter data, including proofing/error checking of incoming GPS data. The USGS arranged to pull raw GPS data from Movebank into the USGS California Condor Management and Analysis Portal (CCMAP) (https://my.usgs.gov/ccmap) for production and dissemination of a daily map of condor movements including various automated alerts. Further, the USGS developed an automatic archiving system for pulling raw and proofed Movebank data into USGS ScienceBase to comply with the Federal Information Security Management Act of 2002. This improved data management system requires minimal manual intervention resulting in more efficient data flow from GPS data capture to archive status. As a result of the project's success, Pinnacles National Park and the Ventana Wildlife Society California condor programs became partners and adopted the same workflow, tracking, and data archive system. This GPS tracking data management model and workflow should be applicable and beneficial to other wildlife tracking programs.
\end{abstract}

\footnotetext{
${ }^{1}$ U.S. Geological Survey

${ }^{2}$ Cherokee Services Group

${ }^{3}$ U.S. Fish and Wildlife Service

${ }^{4}$ The Ohio State University

${ }^{5}$ Max Planck Institute for Ornithology

${ }^{6}$ Cellular Tracking Technologies, LLC
} 


\section{Introduction}

In 2013, U.S. Fish and Wildlife Service (USFWS) staff in the Pacific Southwest Region recognized the need to develop and implement an improved Global Positioning System Data Capture, Delivery, and Archive System (System) to support research and management of the southern population of the Gymnogyps californianus (California condor; hereafter referred to as "condors"). One objective was to develop a data management system for the Hopper Mountain National Wildlife Refuge Complex (Complex). Refuge staff recognized that the new management model needed to work for other condor populations and be a flexible system that could be used by other USFWS wildlife species tracking programs. A basic tenet of this project was that the practices and solutions developed through this project would have broad applicability and that other unrelated species tracking efforts could modify or adopt these practices to support a broad spectrum of species tracking needs. The USFWS coordinated with the U.S. Geological Survey (USGS) to request funding through the Science Support Partnership (SSP) Program. The funded proposal included (1) collaborating with Cellular Tracking Technologies, LLC $^{\text {TM }}$ (CTT) (https://celltracktech.com/) for the acquisition and testing of a new Global System for Mobile Communication (GSM) global positioning system (GPS) transmitters; (2) field testing GSM/GPS transmitters on condors at the Complex; (3) providing Argos/GPS and GSM/GPS data storage and value-added data management; (4) integrating workflows with the animal tracking Web site Movebank (www.movebank.org); (5) ensuring Federal Information Security Management Act of 2002 (FISMA) compliance when utilizing data repository services in the USGS ScienceBase Project; (6) deploying an automated and customized daily movement map and movement/nonmovement alerts through ScienceBase; and (7) implementing archive management in ScienceBase. The initial concept was broadened to include GSM/GPS data acquired with transmitters from Microwave Telemetry, Inc. ${ }^{\text {TM }}$ (MTI) (http://www.microwavetelemetry.com/index.cfm) and inclusion of condor GPS data from the Pinnacles National Park and the Ventana Wildlife Society (VWS).

The California Condor Recovery Program is a multiorganization effort to manage and recover the endangered condor throughout its historic range. At least a dozen different organizations are directly involved with condor recovery through both captive and wild programs in the western United States and Mexico. Three organizations in central and southern California manage the field aspect of condor recovery for the California population (the other two populations are in Arizona and Baja California). Pinnacles National Park and the VWS manage the central California field program, and the USFWS manages the southern California field program. The USFWS "GPS Data Management Manual" (Mendenhall, 2014) previously identified the use of GPS technology as a primary means by which field managers at each site could learn about condor habitat use and threats to condors across the landscape. As of 2013, all three organizations managing the field condor program in California employed the use of GPS transmitters. The southern California group had 29 of 72 condors (40 percent) with GPS transmitters, whereas 29 percent of the central California group had GPS transmitters (13 of 34 managed by Pinnacles National Park and 6 of 32 managed by the VWS).

This project addresses identified needs from the "California Condor (Gymnogyps californianus) 5-Year Review: Summary and Evaluation” (U.S. Fish and Wildlife Service, 2013). The ability to locate, manage, and retrieve condors is one of the key priorities of the Condor Recovery Plan. The System described in this report improves the ability to monitor and manage the central and southern California condor populations on a daily basis and provides the infrastructure for acquiring and managing GPS data from the other condor populations. This information is important for the accomplishment of recovery goals because it will allow recovery field staff to identify potential areas of range expansion, monitor foraging activity, and identify the use of nonproffered food in order to protect individuals and groups of condors from real and potential threats. 
The USFWS manages approximately 72 condors in the southern California group of the California population and maintains GPS units on approximately 40 percent of these birds. This number changes throughout the year depending on deaths, chick survival, and captive releases within the population. Prior to 2004, the Complex purchased only Argos (Doppler) Platform Transmitter Terminals (PTTs). At the onset of this project, Complex field managers employed 29 Argos/GPS PTT units (Argos/GPS PTTs; MTI; fig. 1) to track condor movement. Each unit weighs 50 grams (g) and is designed to fit on a patagial tag affixed to each condor by way of a piercing. Staff members attach or remove GPS units from free-flying condors that are at least 1 year old during recapture events twice a year when field managers test blood in each condor for lead poisoning. Sampling is biased toward breeding birds and an equal sex ratio. Staffs also manage separate very high frequency (VHF) telemetry units (used to signal mortality) attached to the condor's tail. Trapping success rate varies each year with some condors never venturing near the walk-in trap sites for the entire year.

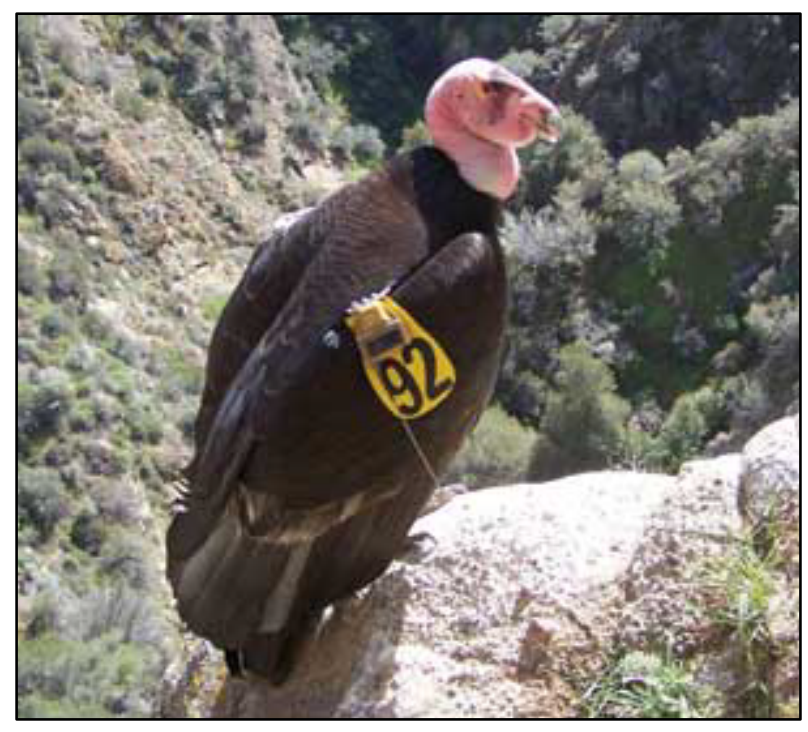

Figure 1. California condor with a Platform Transmitter Terminal-100 50-gram solar patagial Argos/global positioning system from Microwave Telemetry, Inc. ${ }^{\text {TM }}$ (Photograph by Joe Burnett, Ventana Wildlife Society).

Location records generated from Argos/GPS PTT units are recorded hourly during the daytime and are accessible to field staff at a 12-hour or greater delay. The GPS-derived location data inform almost every aspect of the day-to-day management of condors. Field managers use locations to assess how condors are using the landscape and where best to direct staff to gather more data, mitigate problems, or investigate potential issues on any given day. Specifically, GPS location data can lead staff to habituation sites, potential lead exposure events, micro-trash sources, condor mortalities, and nest sites. These location data also support short- and long-term condor research.

Initial efforts to track movements of condors were dependent on Argos/GPS and Doppler data collected from 29 MTI Argos/GPS PTT units. In addition, separate movement data were also being acquired and managed by Pinnacles National Park and the VWS. The initial data flow model is shown in figure 2 . The hosting and maintenance of this model became problematic for multiple reasons. 
1. A primary concern was dependence on the manual mapping between the GPS transmitteridentifier (ID) and the individual condor-ID. The need to utilize separate spreadsheets for each data source (Complex, Pinnacles National Park, and the VWS) and the use of a manual update process were prone to error. The process made it difficult to associate some transmitter-IDs with condor-IDs.

2. There was a designed latency in the evaluation of the data.

3. The model did not support versioning or data archive. The FISMA mandates that all Federal data be maintained on certified systems. The original model did not support a workflow to feed data into an FISMA-compliant repository and archive.

4. There was no mechanism to alert refuge or regional staff about potential issues or problems with any one condor or transmitter. There was no support for automated alerts identifying lack of movement by individual condors or identifying clusters of condors by way of an automated daily map.

5. Research and management required information on long periods of stationary activity including mortality. Although all condors had two VHF transmitters attached to their tails that could transmit a mortality signal, staff did not always receive the signal.

6. Argos/Collecte Localisation Satellites (CLS ${ }^{\mathrm{TM}}$ ) America provided one location fix per hour but researchers and management often required locations every 1-15 minutes.

7. Lower cost options, including cellular GPS, were becoming available and were deemed necessary for long-term monitoring.

8. The USGS office maintaining the scripting and download process was unable to provide adequate long-term support due to increasing fiscal challenges. 


\section{INITIAL USFWS GPS DATA WORK FLOW}

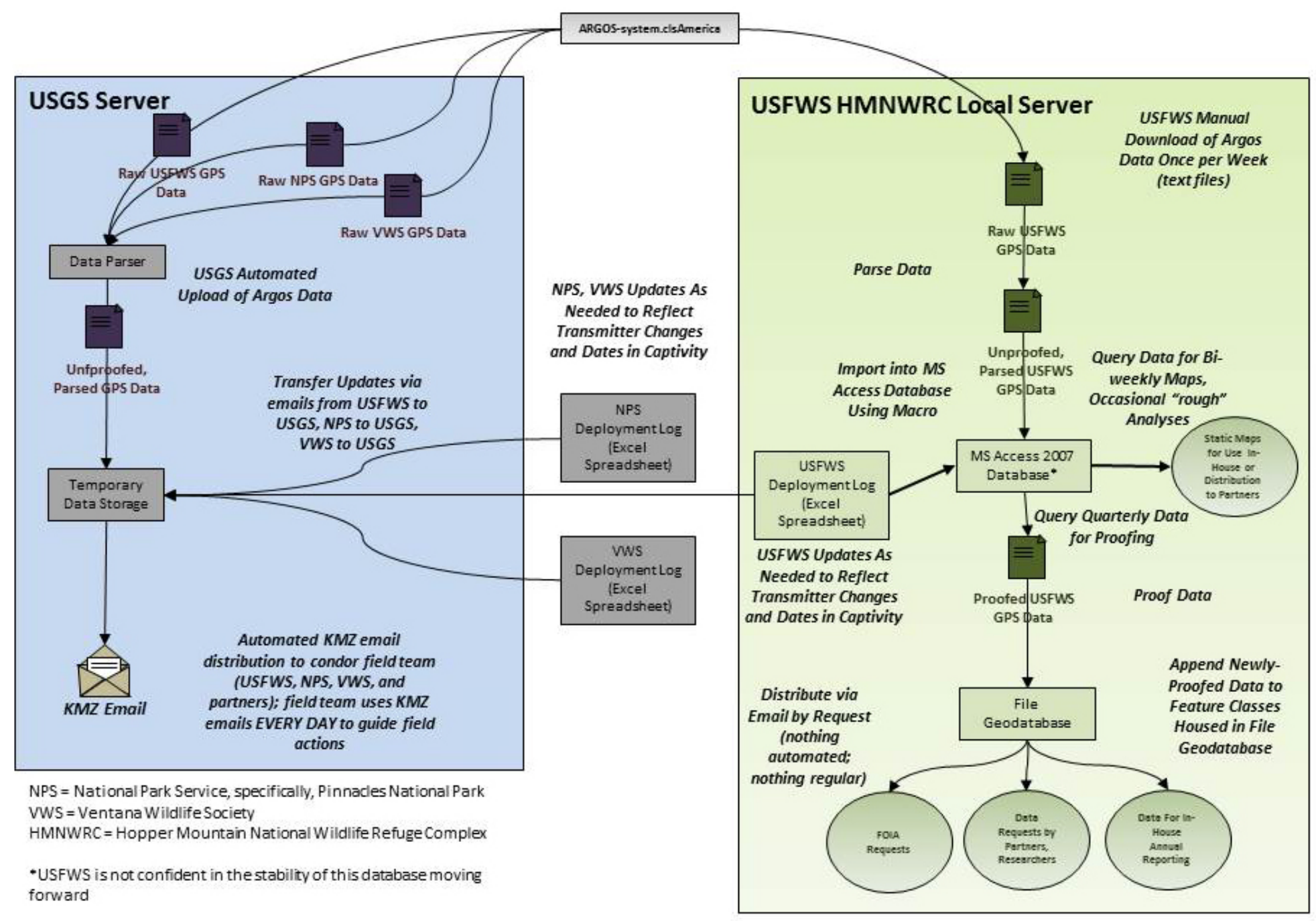

Figure 2. Initial U.S. Fish and Wildlife Service, Pinnacles National Park, and Ventana Wildlife Society global positioning system data workflow (L.C. Mendenhall, U.S. Fish and Wildlife Service, unpub. data, 2015). [FOIA, Freedom of Information Act; GPS, global positioning system; KMZ, zipped keyhole markup language file; MS, Microsoft ${ }^{T M}$; USFWS, U.S. Fish and Wildife Service; USGS, U.S. Geological Survey] 
Improvements were incorporated into the original model prior to implementing this project, but inefficiencies remained. To rectify these issues, we identified processes that could be automated. For example, proofing evolved to using simple queries to check that transmitter-IDs were associated with the correct condor-IDs. Because staff made manual corrections, there was still potential for error. Another example was the use of the Geospatial Modelling Environment (GME) to calculate step lengths between consecutive location fixes, remove outliers (grossly incorrect location fixes), and log location fixes that were removed (7-10 each year). Although this methodology worked, the staff found the use of GME time consuming and inefficient. Lastly, a detailed protocol was developed to allow users with little or no geographical information system (GIS) or Microsoft ${ }^{\mathrm{TM}}$ Access experience to proof the GPS data. A full day was required to proof 3 months of data. These improvements, although significant, were not considered sufficient to warrant suggesting this GPS data capture and management model to offices managing other condor populations or wildlife species. Instead, staff requested a more efficient GPS data management model.

At the request of the Complex, Pat Lineback, Regional GIS Coordinator, Pacific Southwest Region (Region 8), USFWS, and Tim Kern and Robert Waltermire, USGS, developed a Science Support Partnership proposal. The USGS accepted and funded this proposal for a fiscal year 2014 startup and an anticipated duration of 1 year. The initial partners included Pat Lineback, the Complex, Movebank, USGS, and CTT. Pat Lineback handled coordination between USFWS Region 8 and the Complex. Movebank started working with the Complex earlier in 2013 concerning wildlife tracking issues. The USGS provided GPS, programming, and data archive capabilities utilizing ScienceBase. Cellular Tracking Technologies, LLC ${ }^{\text {TM }}$ provided newly designed GSM/GPS patagial mount transmitters for the condors. David Douglas, USGS, ensured continuity in data delivery, management, and deployment of the daily map of condor tracking data.

The USGS awarded funding on October 25, 2013, under Project ID 14-R8-03 with Pat Lineback designated as the USFWS Project Officer and Robert Waltermire designated as the USGS Principal Investigator. Planning immediately began for a project kick-off meeting, held in Ventura, California, December 17-18, 2013, with participants from all of the partners mentioned above (appendix 1). Project objectives were modified at this meeting and finalized through conference calls and email exchanges.

The project team developed several objectives that helped define the proposed System. These objectives resulted in rejecting some existing model components, modifying other components, and introducing new components. This report documents the development of the System and the implementation of each project objective. Additional detailed information concerning implementation of the system from a user perspective is presented by Mendenhall (2014).

\section{Objective 1-Streaming Global Positioning System Data into Movebank}

Prior to the beginning of this project, mechanisms were established to stream Argos data from MTI GPS PTTs into Movebank. The MTI Argos/GPS data stream included both Doppler and GPS data. The MTI GSM/GPS data stream contained only GSM/GPS data. An objective of this project was to have a mechanism to stream CTT data into Movebank, which would allow the USGS to pull and integrate data from all sources (Argos/GPS, MTI GSM/GPS, and CTT GSM/GPS) for archive and assessment.

\section{Objective 2-Associating Transmitter-Identifier with Condor-Identifier}

A long-standing issue was associating transmitter-IDs with the condor-IDs. This issue resulted in some early Doppler data being unusable. The operation was open to error because of the need to move transmitters among condors and the manual nature of the recordkeeping. The accuracy of ID records 
was initially dependent on handwritten notes that were manually entered into a database at a later date. To streamline ID management, one objective of this project was to have Movebank develop/enhance a Web-based application for managing IDs.

\section{Objective 3-Proofing Global Positioning System Data}

The data proofing method was time consuming and tedious. A project objective was to have Movebank develop a Web user interface for proofing both Argos/GPS and MTI and CTT GSM/GPS data. Proofing data was to be accomplished without deleting records but rather by flagging erroneous records in the Movebank database. Flagging rather than deleting erroneous data would preserve all data for historical purposes and prevent the accidental loss of data.

\section{Objective 4-Associating Environmental Data with Global Positioning System Tracking Data}

Movebank developed the Environmental Data Automated Track Annotation System (EnvDATA) used to associate global environmental data with animal tracking data. The California condor program may not require Env-DATA, but one objective of this project was to include the potential to make use of Env-DATA.

\section{Objective 5-Moving Data from Movebank to ScienceBase for Archive}

FISMA mandates that Federal agencies and other Federal government offices strengthen and ensure the security of information systems and data. A requirement of this project was to store project data in a FISMA-certified facility for long-term archive. The USGS ScienceBase is designed to be a long-term FISMA-compliant archival system with data replication in the USGS Cloud Hosting Solution. ScienceBase adheres to all relevant USGS/Department of the Interior security standards and is monitored to ensure that it continues to maintain the required security protections. ScienceBase was designed to capture, manage, and serve science data products, and provides map services, visualization, and data download capabilities. Archiving all condor tracking data in ScienceBase became another objective of this project.

\section{Objective 6-Automating the Daily Map}

The Complex requires a daily map of condor movements for research and management

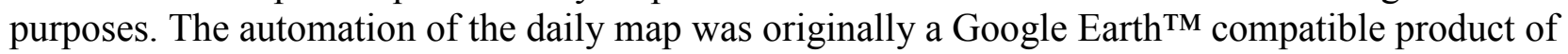
David Douglas, USGS, which later served as a precursor to Movebank's (Kranstauber and others, 2011) live-update products. The condor daily map was processed and disseminated by the USGS. An objective of this project was to simplify and streamline the existing data management model by fully automating the construction and deployment of the daily map and to have it utilize data pulled from Movebank. The objective evolved into multiple subobjectives: symbolize the movement/nonmovement of condors on a daily basis for the previous 7 days, symbolize clusters of condors, symbolize condor locations to meet the needs of the Complex staff, and distribute the information for visualization in a KMZ file automatically emailed to a pre-determined list of clients.

\section{Objective 7-Automating Alerts Indicating Transmitter Readiness and Condor Behavior}

Researchers and managers require automated notification of transmitter readiness and condor behavior that was not a function of the initial data management model. The following objectives were included: 
1. Design a way to verify that an individual condor had an association with an active deployment before sending an alert for nonmovement or nontransmission of data. The system needed to determine that a transmitter was deployed on a free-ranging condor by first checking if a deployment record existed that had no "deployment_end_type" entry for a specific condor.

2. Send a notification if the transmitter stopped functioning, defined as a transmitter not sending data for a week or more.

3. Send notification of nonmovement, defined as a condor moving less than $(<) 100$ meters in 24 hours.

4. Send notification of whether a condor is airborne or on-the-ground, defined using the ground speed attribute.

5. Ensuring that Argos/GPS and MTI and CTT GSM/GPS data alerts were sent separately.

\section{Objective 8-Managing Legacy and Current Data}

Legacy data are defined as unproofed Doppler tag data (2001-8) from the MTI (Doppler) PTT units. An objective of this project was to determine if these legacy data could be processed and made usable. In contrast, current data are defined as nonlegacy data and include proofed MTI Argos/GPS PTT unit data (GPS tag data 2005-13) and current MTI and CTT GSM/GPS data suitable for analysis and display. Coarse Doppler data, also collected from the MTI PTT units, would only be used if GPS data sources failed. The objective includes what data to make available to researchers, managers, and the public, and how to make the data available.

The following objectives were considered to be too involved for this short-term (1 year) project, were not considered important enough to be included at this time, or were determined to be unnecessary.

\section{Objective 9-Testing the Functionality of Global Positioning System Transmitters}

An initial project objective was to test various GPS transmitters for accuracy on condors, cost efficiencies, and other factors. This objective included testing GSM/GPS transmitters as compared to transmitters utilizing the Argos system while the transmitters were deployed on condors. This objective was dropped because there was neither the funding nor the time to perform a statistically valid test. It was also considered to be unnecessary since solar powered GSM/GPS units had been successfully deployed on other large birds such as golden eagles (Aquila chrysaetos; Duerr and others, 2012; Lanzone and others, 2012), and testing GPS transmitters was not a USFWS requirement.

\section{Objective 10-Developing and Deploying Geofence Capability}

Developing and deploying geofence capability based on GSM/GPS and Argos/GPS fixes was an initial consideration for alerting USFWS staff about the movement of condors into and out of sensitive areas. An initial version of the new data model included developing a Web-based portal where USFWS staff would submit polygonal Environmental Systems Research Institute, Inc. (Esri) shapefiles defining the geofence boundaries. An automated email alert would be sent to authorized personnel when a transmitter crossed a designated geofence boundary. Cellular Tracking Technologies, LLC ${ }^{\text {TM }}$ has geofence capability built into their system, which could be activated when needed. The USFWS wildlife biologists decided this was an unnecessary capability.

\section{Objective 11-Enhancing the Douglas-Argos-Filter}

The Douglas-Argos-Filter (DAF; Douglas and others, 2012) was used to process Doppler data transmitted from the Argos (Doppler) PTT and Argos/GPS PTT units. Because of the reliability of 
current GPS transmitters and the high quality of GPS data, it was decided not to continue processing the Doppler data. The project team decided not to enhance the DAF.

\section{Objective 12-Consolidating Condor Profiles with the Tracking Database}

A condor profile is a record of historical information about each bird. This information is currently stored separately from the tracking database in the California Condor Studbook. The project team considered consolidating the condor profiles (Studbook) with the tracking database but USFWS personnel decided this was unnecessary.

\section{Objective 13-Including Condor Tracking Data in ServCat}

ServCat is the U.S. Fish and Wildlife Service Catalog housed in the Environmental Conservation Online System (ECOS). ServCat is designed to preserve data and information obtained by the USFWS including geospatial data. The project team considered having ServCat pull the condor tracking data from ScienceBase. Since the data were stored both at Movebank and in ScienceBase, the USFWS decided it was not necessary to also store the data in ServCat.

The basis of the implemented data capture, delivery, and archive system is the automated and managed flow of data and information from GPS sources to users with minimal manual intervention and permanent archive (fig. 3). The Argos/GPS data are uploaded to a satellite and transmitted to Argos servers before being streamed to Movebank servers. The GSM/GPS data from MTI and CTT are transmitted through the cellular network to their respective servers and then streamed to Movebank servers. Movebank implements two filters between the raw and unproofed data: (1) the DAF processes Argos telemetry (Doppler) data and (2) General Purpose Filters automatically proof Argos/GPS and MTI and CTT GSM/GPS data. The Movebank Deployment Manager associates the transmitter-ID with the appropriate condor-ID (manual intervention) before the data continue through the system. Deployment data generated within Movebank are archived on a USFWS server. Unproofed data for the 7 most current days are pulled into ScienceBase on a daily basis and displayed in a daily map for use by authorized researchers and managers. These unproofed data drive various alerts that are automatically emailed to authorized researchers and managers. A data manager performs a quality control check (proofing; manual intervention) of the previous 3 months of data on a quarterly basis. The proofed and unproofed data are pulled to ScienceBase for permanent archive. Data in Movebank and ScienceBase are available for in-house USFWS applications and use by partners. The public has access to proofed condor data only through ScienceBase. The "Methods" section of this report presents detailed explanations of this model. 


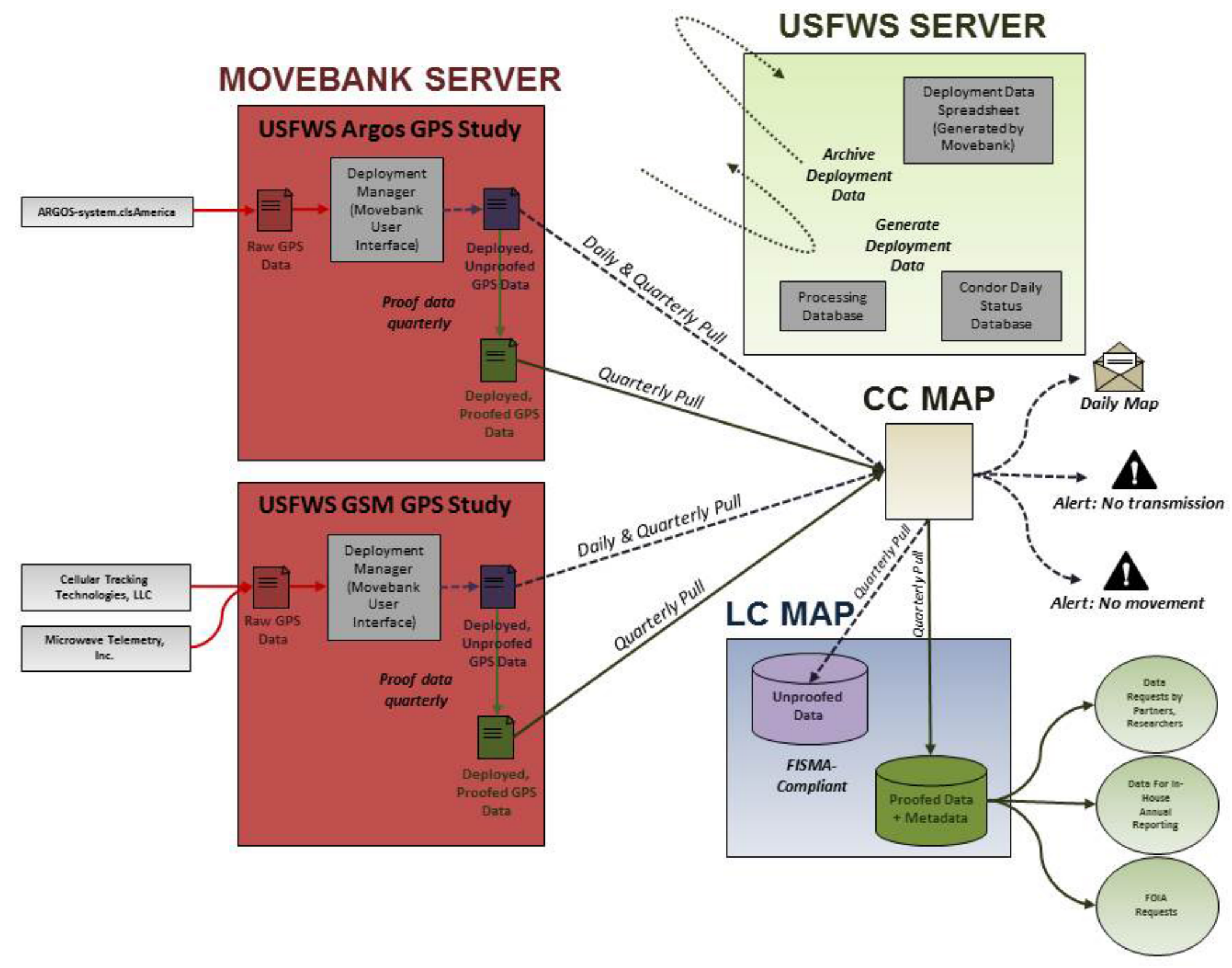

Figure 3. Implemented global positioning system (GPS) data capture and delivery system for managing populations of the California condor. Dashed and solid lines indicate the flow of unproofed and proofed data, respectively (Laura Mendenhall, USFWS). [CC MAP, California Condor 
Management and Analysis Portal; FISMA, Federal Information Security Management Act of 2002; FOIA, Freedom of Information Act; GPS, global positioning system; GSM, Global System for Mobile Communication; LC Map, Landscape Conservation Management and Analysis Portal; USFWS, U.S. Fish and Wildlife Service]

The study area (fig. 4) reflects the approximate range of condor activity in 2012 and 2013 and encompasses more than 5,463 hectares (13,500 acres) in southern and central California within Kern, Santa Barbara, Ventura, Los Angeles, Fresno, and Tulare Counties (USFWS unpublished data). The study area is an ideal location to test GSM technology given its solar energy potential and proximity to cellular towers associated with the urban and suburban communities of Los Angeles, Ventura, Santa Barbara, and Bakersfield.

\section{Methods}

At the time this project was initiated, the California Condor Recovery Program at the Complex was acquiring Argos telemetry data (GPS and Doppler) utilizing 29 MTI transmitters with data transmission by way of satellite to Argos and MTI servers. These data were then sent to Movebank for editing, management, and storage. Since these units also provided Doppler data, Movebank implemented the DAF (Douglas and others, 2012) to process the Doppler data automatically. At the same time, the Complex purchased $10 \mathrm{GSM} / \mathrm{GPS}$ transmitters from MTI with the GPS data ultimately residing in Movebank. The project documented in this report funded the purchase of four CTT GSM/GPS transmitters for the Complex. The GSM/GPS is a telecommunications standard used for digital cellular networks and used for transmitting cellular-based GPS data. The GSM/GPS transmitters offer potential benefits over Argos telemetry data including lower operating costs and richer, more frequent data streams. The delivery of these units was delayed while CTT was testing transmitter housings in cooperation with the Complex. During the testing period, two CTT GSM/GPS transmitters were intermittently acquiring data, which allowed Movebank staff to develop the means of ingesting the CTT data. The availability of three different functioning data streams (Argos/GPS, MTI GSM/GPS, and CTT GSM/GPS) made it easier to develop the solution framework of pulling data into ScienceBase, developing and delivering the daily map and alerts, and establishing an archive protocol. A list of specifications for the GPS transmitters used in this project is provided in appendix 2. As a possible metric of this project's success, in early FY15 the Complex ceased using Argos/GPS and started relying entirely on GSM/GPS technology. 


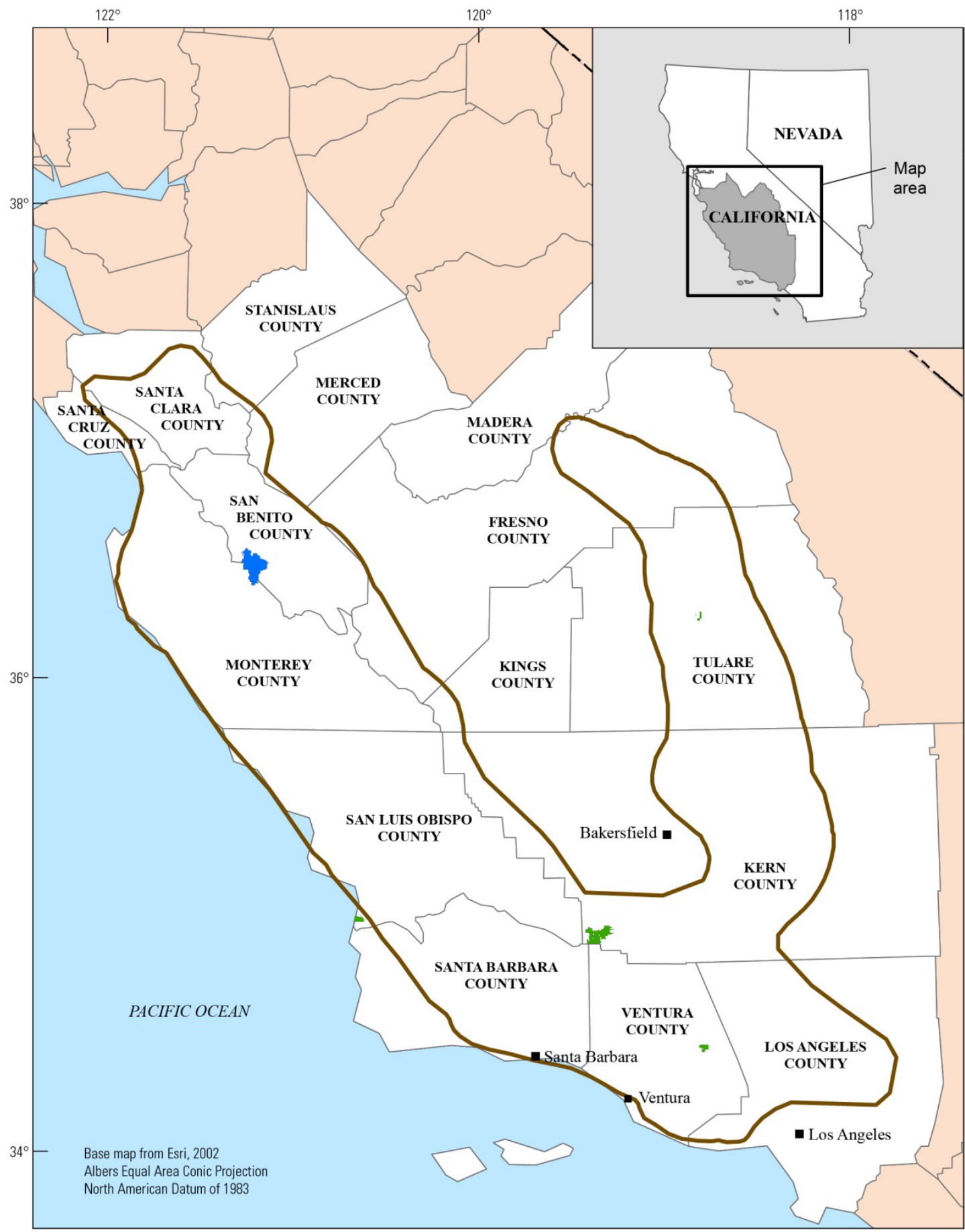

EXPLANATION

Approximate California condor range

Hopper Mountain National Wildlife Refuge Complex

Pinnacles National Park

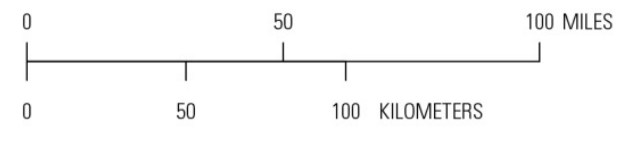

Figure 4. Study area showing approximate California condor range for both the central and southern populations. 


\section{Design, Testing, and Evolution of Prototype Transmitters from Cellular Tracking Technologies, LLC $^{\text {TM }}$}

Two prototypes of CTT GSM/GPS transmitters were developed during the testing period and the second prototype was implemented in the final design. The first prototype had a small footprint (width, 50 millimeters [mm]; height without top posts, $50 \mathrm{~mm}$; height with top posts, $55 \mathrm{~mm}$; thickness, $20 \mathrm{~mm}$; patagial post length, $17 \mathrm{~mm}$ ) but was thicker and less aerodynamic (figs. 5 and 6). It also had a tendency to rotate forward over the leading edge of the patagium, which was undesirable because it tends to enlarge the attachment hole in the wing causing unacceptable damage. These two units were later refurbished and redeployed utilizing the final casing design.

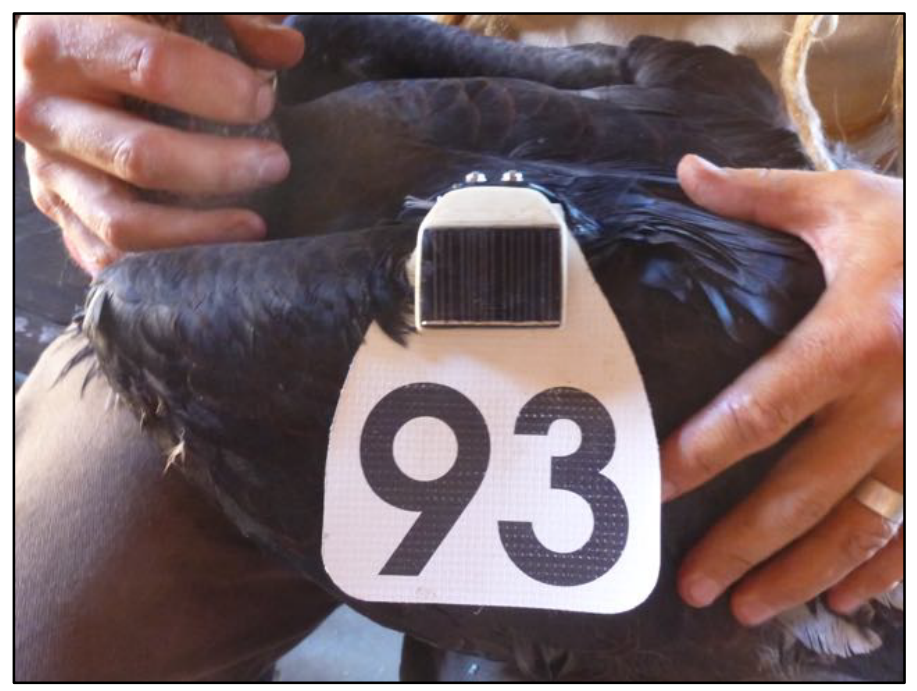

Figure 5. A top-down view of Cellular Tracking Technologies, LLC ${ }^{\text {TM }}$ prototype number 1 with solar panel and separate number tag (Photograph courtesy of U.S. Fish and Wildlife Service).

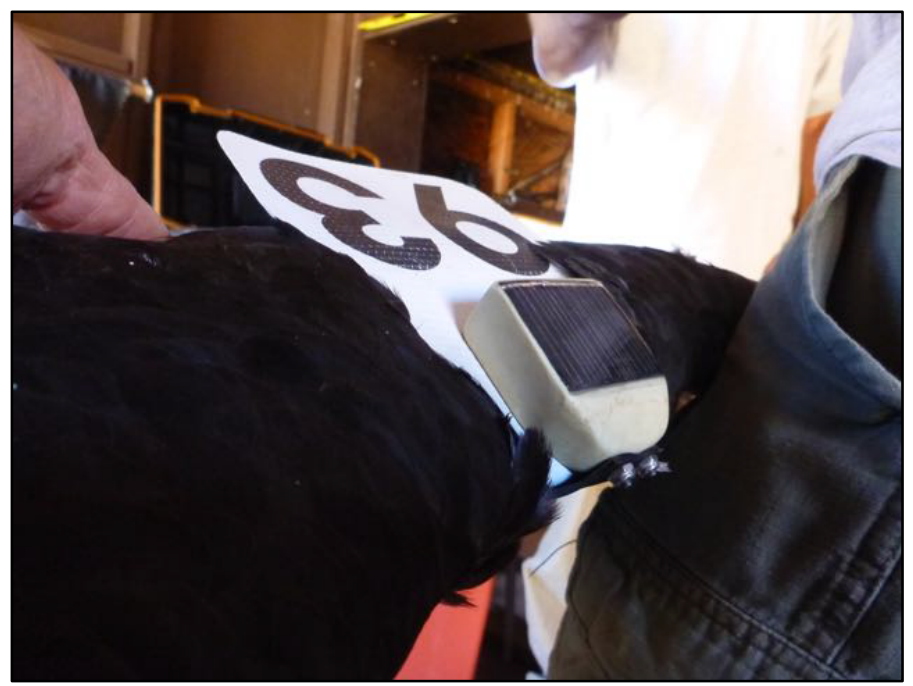

Figure 6. Lateral view of Cellular Tracking Technologies, LLC ${ }^{\text {TM }}$ prototype number 1. Note the small size but bulky shape (Photograph courtesy of U.S. Fish and Wildlife Service). 
After working with the staff of the Complex, the second prototype (number 2) was developed with a larger footprint (width, $82 \mathrm{~mm}$; height without top posts, $61 \mathrm{~mm}$; height with top posts, $67 \mathrm{~mm}$; thickness, $14 \mathrm{~mm}$; patagial post length, $19 \mathrm{~mm}$ ) and a much thinner, more aerodynamic design. The weight remained at approximately $50 \mathrm{~g}$. Prototype number 2 was especially thin on the leading edge and was better at staying in position on the wing. This new design was not prone to rotating forward over the leading edge of the patagium (figs. 7 and 8).

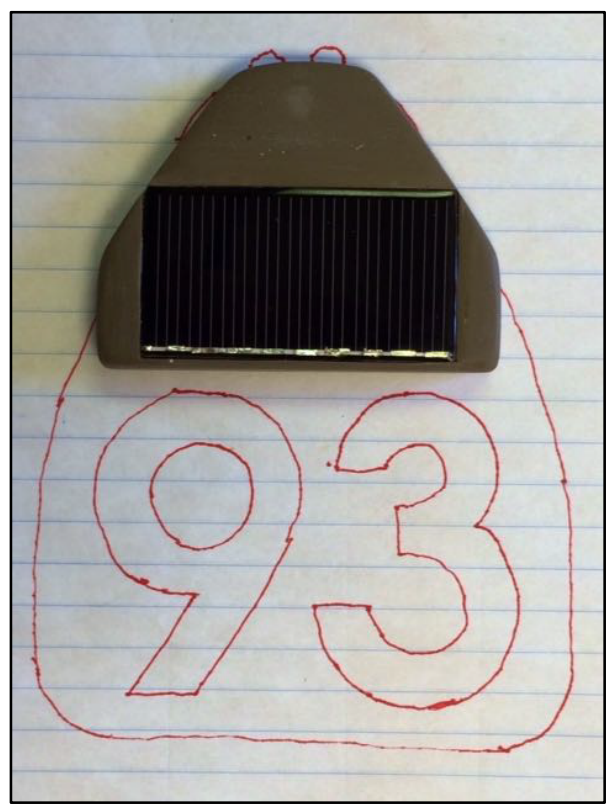

Figure 7. A top-down view of Cellular Tracking Technologies, LLC ${ }^{\text {TM }}$ prototype number 2 (Photograph by Andrew McGann, Cellular Tracking Technologies, LLC ${ }^{\mathrm{TM}}$ ).

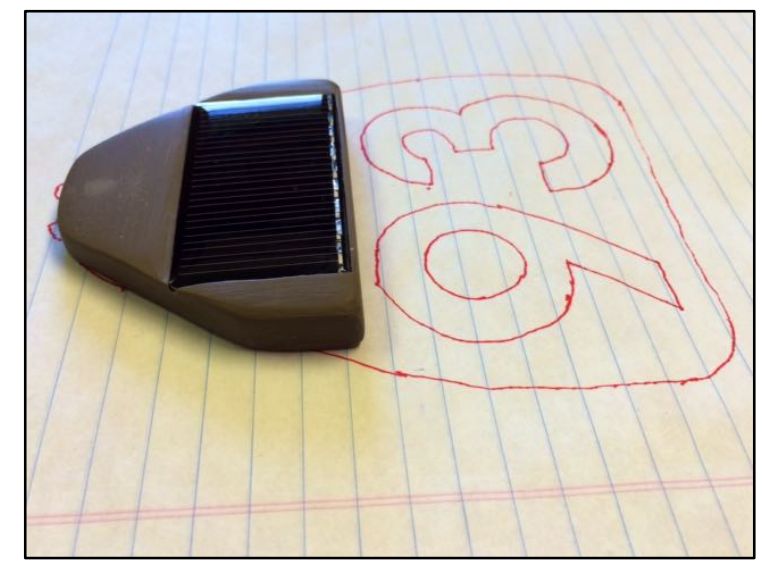

Figure 8. Lateral view of Cellular Tracking Technologies, LLC ${ }^{\text {TM }}$ prototype number 2. Note the thinner, more aerodynamic design (Photograph by Andrew McGann, Cellular Tracking Technologies, LLC ${ }^{\text {TM}}$ ). 
The design of prototype number 2 was used for the four transmitters purchased for this project (fig. 9). The staff at the Complex must periodically rotate transmitters from one wing to the other. This rotation is implemented to allow the wing tissue to heal where the transmitter and number tag are attached. A poorly placed hole or too much rotation by the transmitter can make the hole larger and cause permanent damage to the birds. Some birds currently have large holes in their wings and Complex personnel prefer not to put transmitters on those wings.

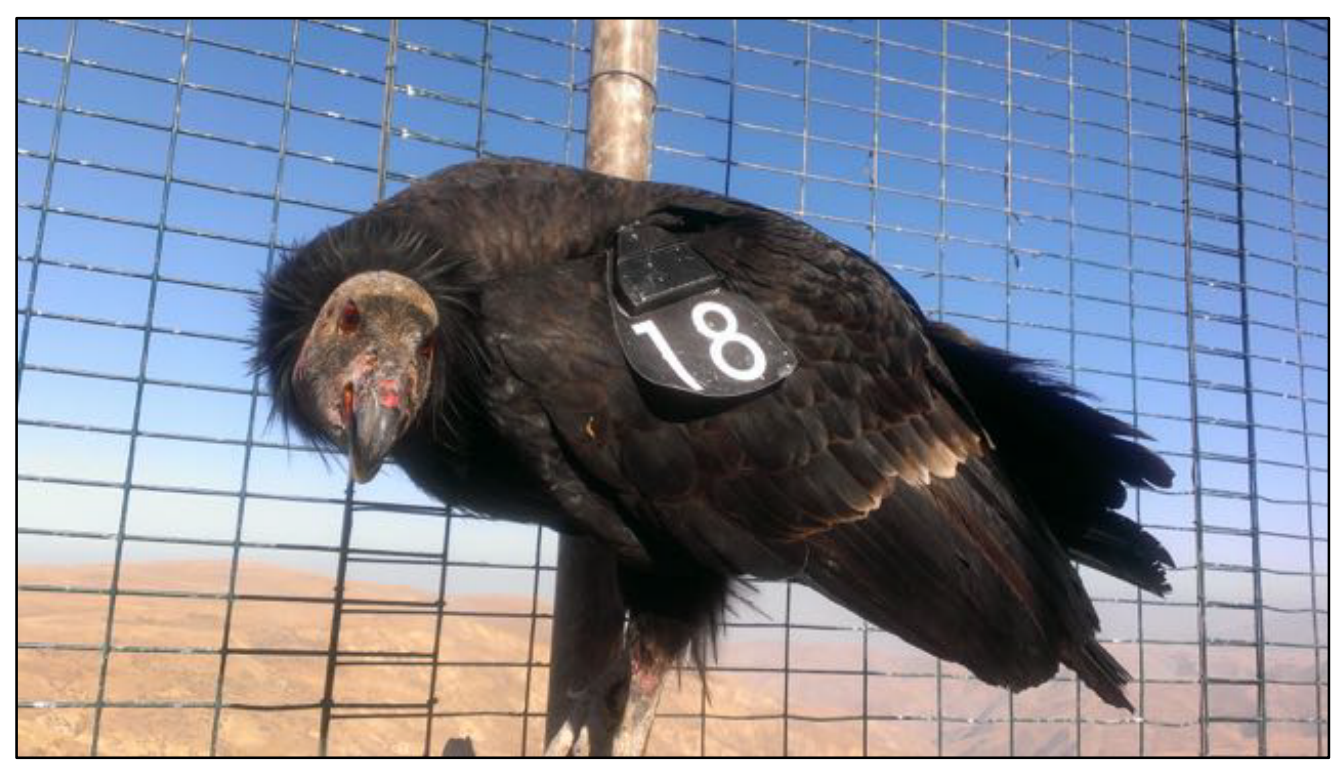

Figure 9. The final Cellular Tracking Technologies, LLC ${ }^{\mathrm{TM}}$ transmitter design shown mounted on the patagium on a California condor (Photograph by Joseph Brandt, U.S. Fish and Wildlife Service).

The GSM component of the CTT transmitter uses a cellular modem to connect to the Internet and transmit the GPS data to the CTT servers. Cellular Tracking Technologies, LLC ${ }^{\text {TM }}$ can change the deployed transmitter parameters over the cell phone network, referred to as an over-the-air (OTA) update. The acquisition rate of a fix can be adjusted between 1 and 15 minutes in operational mode depending on the requirements of the USFWS. The CTT units in this study were set to acquire a fix every 15 minutes from sunrise to sunset with no fixes during nighttime. The MTI units were set to acquire a fix as often as every minute during full daylight hours and tapering off to once each hour during nighttime. The MTI and CTT units are capable of acquiring GPS fixes during nighttime, transmitting the data at night, and are reprogrammed remotely. The units store data when they are out of cellular coverage, and they transmit the data once cellular coverage is regained. The CTT units store greater than 100,000 location fixes onboard and MTI units store 258,000 location fixes onboard. The GSM/GPS devices available from MTI are PTCRB/CTIA/FCC certified (CTIA, 2015; PTCRB, 2015a; PTCRB, 2015b). The specifications and capabilities for GPS transmitters are changing rapidly. The specifications mentioned here and presented in appendix 2 were current at the time this project was initiated and are continually being enhanced. 


\section{Objective 1-Streaming Global Positioning System Data into Movebank}

The USGS entered into a Cooperative Agreement with Dr. Gil Bohrer at The Ohio State University affiliated Cooperative Ecosystem Studies Unit (CESU) to implement the portion of the data management model in Movebank. The first task was to develop the capability to ingest CTT GSM/GPS data into Movebank to complement the Argos/GPS and MTI GSM/GPS data streams. Movebank began ingesting CTT GSM/GPS as a live streaming data source on May 18, 2014. The USFWS and CTT confirmed that all of the data attributes reported from the tag were being imported correctly into Movebank. The process of establishing a live feed from GPS transmitters into Movebank is described in steps 1-3 in Mendenhall (2014), and the process of uploading data obtained prior to establishing a live feed is described in step 4 in Mendenhall (2014). As condor tracking continues at the Complex, there may be a need to add additional GPS transmitters to the live feed into Movebank (task 2 in Mendenhall, 2014).

The registered user owns data in Movebank. Registered users, such as the data managers in the USFWS, create studies in Movebank and then have complete control over defining access rights to all information in the study. The data owner(s) for a study manages access for three potential user groups: data managers, collaborators, and the public. For example, a data owner can

- make the study completely invisible to everyone else;

- grant limited access to users added as "collaborators" to the study (for example, allowing them to view one or more tracks on a map but not download data);

- allow others to view a written summary of the study but nothing else; and

- grant full access, including download privileges.

In addition, anyone who has permission to download data can be required first to accept the terms of use defined by the data owner. All condor data in Movebank are invisible to everyone except the USGS and collaborators defined by the USFWS.

\section{Internet Security Protocol in Movebank}

Server storage.- The Movebank servers are hosted at the Garching Computing Center in Germany, which is owned and managed by the Max Planck Society.

Secure Sockets Layer (SSL) protocol.- The Movebank Web site is run using a SSL/Transport Layer Security (TLS) protocol. With this protocol, all communications and transfer of data are encrypted. Preventing illegitimate users. - The Web site checks all email addresses that attempt to register against lists of known spammers, and users must confirm that their email address is valid before completing their registration.

Mapping locations. - When tracks are mapped on Google ${ }^{\mathrm{TM}}$ maps, the coordinates are first converted to raster images, so precise locations are not transmitted to Google ${ }^{\mathrm{TM}}$.

\section{Objective 2-Associating Transmitter-Identifier with Condor-Identifier}

Movebank allows users to define unique identifiers for animals (animal-IDs; in this case, condor-IDs), transmitter-IDs (also called Tag-IDs), and the time periods transmitters are deployed on animals (deployment periods). These metadata are defined using the Web-based Movebank Deployment Manager. Once these metadata are defined in a user's study, the user need only provide the transmitterID/animal-ID and Movebank will automatically associate the location data with the correct deployment and animal-ID ("animal track"). As the user updates the metadata, such as when a transmitter is moved from one condor to another, the data will be reassigned to the correct animal-ID. Further discussion of the Deployment Manager and an example are provided in step 5, and tasks 4 and 5 by Mendenhall (2014). 
This method of managing data and metadata allows data providers to send raw data, which contain only the transmitter-ID, to Movebank. The data owner can organize the incoming dataset by providing the metadata (transmitter-ID/animal-ID association) and then receive updates by email on the movement of tagged animals. Since 2011, Movebank has allowed users to have data from Argos PTTs automatically sent, decoded, and stored in their study. Prior to and during the course of this project, Movebank added similar interfaces for several GSM tag types, including MTI GSM and CTT GSM transmitters. The USFWS was one of the first test users of these new data feeds and provided critiques that improved the data feed process and Web interface.

The Deployment Manager interface existed prior to this project but was modified following discussions between USFWS field managers and Movebank programmers. Condor GPS deployments are defined based on the trap and release times (that is, times in captivity), and not attachment and removal of GPS units. The USFWS worked with Movebank to improve the "deployment end type" metadata field by having Movebank add "captured" as one of the available options (see the Movebank Attribute Dictionary at https://www.movebank.org/node/2381). The "deployment end type" lets the user classify how the deployment ended (for example, equipment failure, the death of the animal, or removal of the transmitter). The "captured" option allows the user to specify that the transmitter remained on the animal, but that the animal was confined, and the data no longer represent movements of a free-ranging animal. In addition, a condor management-specific lexicon was developed for applicable fields in the Deployment Manager, so field managers across release sites could use each Deployment Manager field consistently (Mendenhall, 2014).

\section{Objective 3-Proofing Global Positioning System Data}

The Event Editor in Movebank (https:/www.movebank.org/node/42) allows users to view their data in tabular format and on a map, and edit the dataset. Two commonly used features are (1) the ability to add and remove attributes from the dataset and (2) the ability to flag records as outliers. This second feature removes them from the visible points on the map and allows them to be excluded from analysis, without deleting them from the dataset. Outliers can be flagged manually using the "manually marked outlier" attribute. Argos telemetry data that use Argos data filters use an "algorithm marked outlier" attribute and automatically flag records based on the Argos Location Class attribute. The DAF codeveloped at USGS and Movebank (Douglas and others, 2012) has been superseded by the Event Editor. In collaboration with the USFWS, Movebank added general purpose data filters and proofed data attributes to the proofing technique.

\section{General Purpose Data Filters}

General purpose data filters run automatically using user-defined parameter values, storing their results in the "algorithm marked outlier" attribute. These filters run on any tracking data (not Argosspecific) and allow users to flexibly flag data based on three filters that address common errors in tracking data (https://www.movebank.org/node/33529):

Duplicate filter.-Flags duplicate records that are sometimes provided by the transmitter or accidentally added through file uploads. The user defines which attributes are used to define duplication.

Speed filter. - Calculates the speed that would be required to travel between consecutive locations on a track, and flags records that would require the animal to have traveled at an unrealistically high speed. The user defines the maximum plausible speed of the animal and the maximum error in the location estimate and chooses one of the three ways of calculating speed.

Value range filter.-Flags records based on values of any attribute in the dataset. This filter allows the user to define the attributes and values used. For example, the users can choose to flag records with a 
location error estimate greater than X meters, a fixed type of 1 , or locations outside a specific latitude or longitude range.

New "Proofed" Data Attribute

A new data attribute, "Proofed," can be used to indicate whether or not individual records have been processed manually, checked for quality assurance, and proofed. In the Event Editor, a data owner can add this attribute to the dataset, highlight one or a section of records (which can easily be confined to a time period or an individual transmitter or animal), and assign "true" or "false" to the "proofed" attribute of the records. The USFWS has proofed all existing GPS data and uses this data attribute technique for proofing all incoming data.

\section{Objective 4-Associating Environmental Data with Global Positioning System Tracking Data}

The Env-DATA system in Movebank provides a graphical user interface (GUI) and an application program interface (API) for easy access to a large array of remote sensing and weather reanalysis datasets (Dodge and others, 2013; Movebank, 2015). The Env-DATA provides efficient methods to examine relationships between observed or hypothetical animal movements (time-series of biological observations) and a breadth of information about environmental conditions. This system also provides the data to support the development of movement models and forecasts and provides the data to test hypotheses about the relationships among the environment, animal movement, and habitat use. The tool is useful for studying movement at any scale. Dr. Gil Bohrer applied the system in response to the USFWS request to study the distribution of uplift sources around a proposed new condor release site in northern California and southern Oregon (fig. 10).

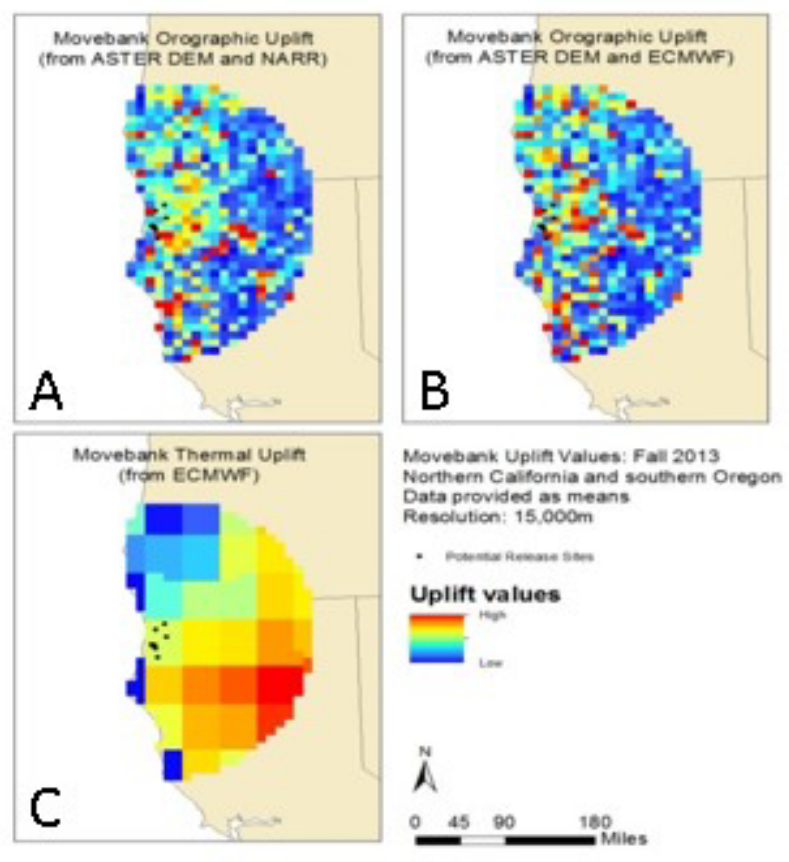

Figure 10. Distribution of orographic uplift. $A$, calculated with wind data from the North American Regional Reanalysis [NARR] model reanalysis dataset. $B$, calculated with data from the European Centre for Medium-Range Weather Forecasts [ECMWF]. C, thermal uplift availability during the fall season. Based on 2013 data (Dee and others, 2011; Image courtesy of Movebank). [ASTER, advanced spaceborne thermal emission and reflection radiometer; DEM, digital elevation model] 


\section{Objective 5-Moving Data from Movebank to ScienceBase for Archive}

Maintaining an archive of the condor GPS tracking data in compliance with the Federal Information Security Management Act of 2002 was a primary reason for establishing this project. The Complex's data archival and documentation system was inadequate with potential for catastrophic data loss between data backups. This objective is fulfilled by automated and regular "pulling" of the unproofed and proofed Argos/GPS and the MTI and CTT GSM/GPS data from Movebank directly into ScienceBase.

The initial archive pulled the complete database (except the legacy data) from Movebank. Succeeding archives are generated on a quarterly basis. Specifically, the archive for a quarter's worth of data is generated 1 month after the quarter ends. For example, the archive for the January-March quarter is archived on the first Sunday in May with the month of April reserved for proofing the data. The USFWS staff have established a deadline of proofing a quarter's data within 1 month of the end of the quarter. Each "pulled" project in Movebank gets stored as a separate archive in ScienceBase, and within each project Argos/GPS data are stored separately from the GSM/GPS data. Movebank provides their standard and evolving attribute list for use in ScienceBase to complement metadata.

Legacy data will also be archived with metadata in ScienceBase and will be accessible by the USFWS and by the public upon request to the USFWS. The public does not receive access to any condor data stored in Movebank and is only provided access to proofed data in ScienceBase. The public acquisition of legacy and unproofed data will be through a request to the USFWS or the Freedom of Information Act (FOIA; 5 U.S.C. § 552) process.

Each quarter, during new archive creation, a shapefile is generated and imported that contains only proofed, deployed, GPS (non-Argos Doppler) data. This shapefile is then automatically exposed as a Web Map Service (WMS) through ScienceBase.

\section{Metadata in ScienceBase}

The Federal Geographic Data Committee Content Standard for Digital Geospatial Metadata is the format used for all metadata and includes all the required time and location metadata (geospatial metadata). All GPS attribute fields are defined and available in ScienceBase. Only the start and end dates will change with each database download.

The parent condor folder has a footprint of the State of California. The Active and Legacy data subitems will have minimal global metadata that can be augmented as needed. The GPS folder under Legacy data will have more specific information about the format of the legacy dataset. The items under active data will have metadata that are generated automatically during processing (which is limited to basic information and start and end dates). These latter metadata should not be updated because the details about the dataset occur at the parent folder level, whereas the date stamps are maintained at the child level.

\section{Objective 6-Automating the Daily Map}

The Complex requires the production and delivery by email of a daily map of the previous 7 days of condor GPS locations. The daily map symbolizes the movement and nonmovement of condors. The daily map is provided in KMZ format, is delivered automatically by the California Condor Management and Analysis Portal (CCMAP) only to USFWS staff each day, and is not made available to the general public. Two KMZ files are generated every day and both are sent to the entire email list of recipients. Personnel at the Complex have control of the email list of recipients. The first KMZ file contains the locations for the two projects (Argos/GPS data and GSM/GPS data) for the southern 
California condor populations. The second KMZ file contains the locations of the two Pinnacles National Park (Argos/GPS data and GSM/GPS data) and the two VWS projects (Argos/GPS data and GSM/GPS data).

\section{Visualization and Symbology}

Visualization options and symbology of the daily map are customized according to the requirements of the Complex staff. Stationary locations are displayed as a square with an internal " 0 " (Argos/GPS) or an internal "X" (GSM/GPS). Locations for a moving bird are displayed as a circle with an internal "0" (Argos/GPS) or an internal "X" (GSM/GPS). Squares, circles, and tracks are colored differently for each bird (fig. 11). Visualization options include all or any combination of the following:

- Time Slider: A time slider is displayed that allows temporal viewing of the data.

- Day and Stationary: There is an option for display of a combination of day and stationary locations.

- Stationary/Moving: There are separate stationary and moving options derived from the Movebank "event_ground_speed" attribute where stationary is defined as movement $<10$ kilometers per hour $(\mathrm{km} / \mathrm{h})$. Otherwise, the bird is considered to be moving.

- Day/Night: Identification of the location as being either day or night is based on the Movebank "event.location_lat," "event.location_long," "event.timestamp," and third-party Java code.

- Adults/Juveniles: Age class is defined by the Movebank "individual_exact_date_of_birth" where a juvenile is $<6$ years old, otherwise the bird is considered to be an adult.

- Individual Birds: Individual birds (fig. 11) can be displayed at all locations (points) and the complete flight paths (lines). 


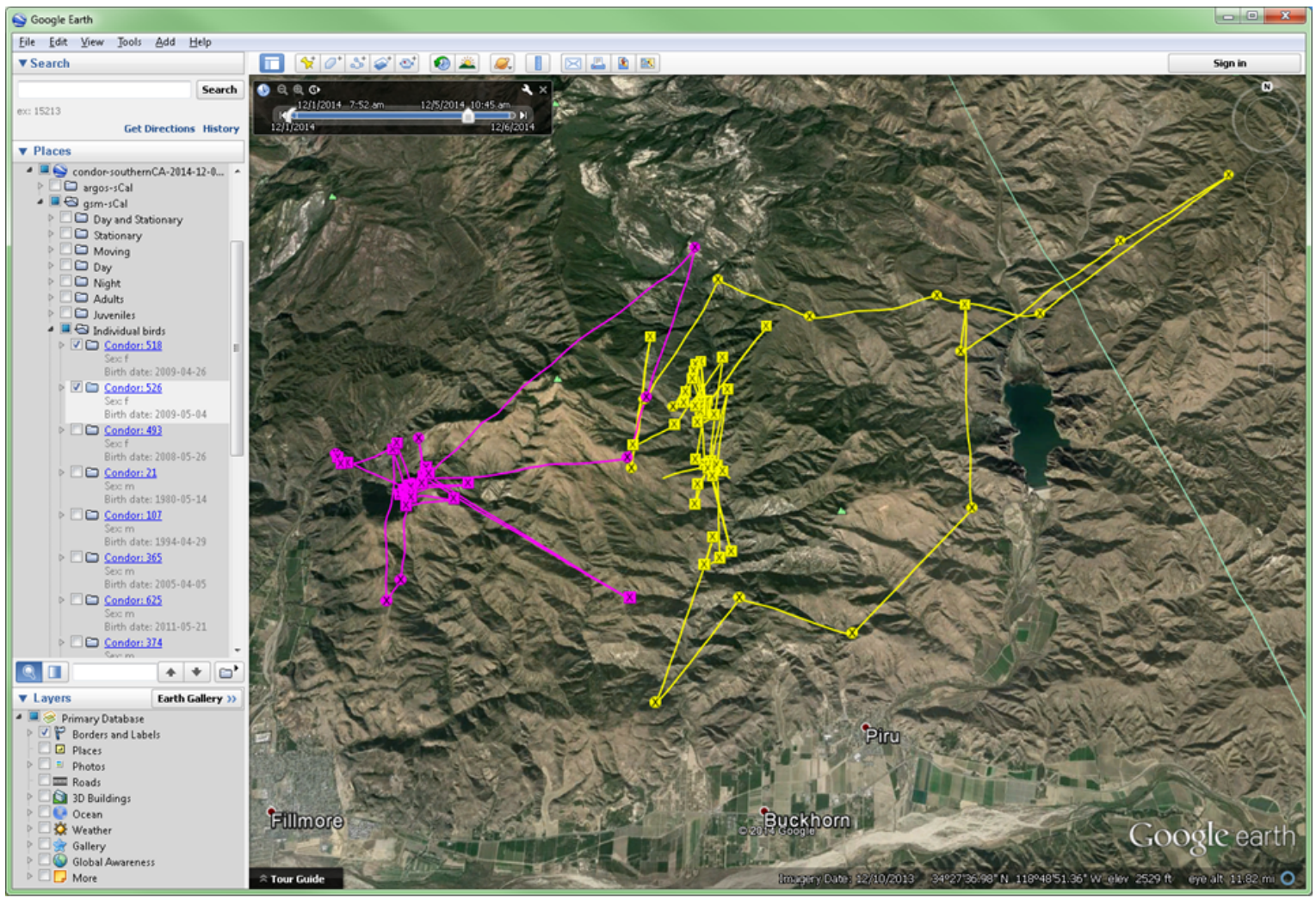

Figure 11. Example display of a KMZ file in Google Earth ${ }^{\mathrm{TM}}$. Locations of two California condors are displayed from the Global System for Mobile Communication/global positioning system data. [KMZ, zipped keyhole markup language file]

- Clusters (10:00 a.m.-4:00 p.m.): Clusters of condors by day can be displayed. Clusters are defined by the Movebank "event.timestamp" and day (10 a.m.-4 p.m.), "event.location_lat," and "event.location_long" where condors are within 100 meters of each other during the day on the ground (speed less than or equal to $10 \mathrm{~km} / \mathrm{h}$ ). Clusters are reported for the previous day and are portioned based on between-group-distance greater than 250 meters. Yellow symbols represent "nonpersistent" clusters ( $<3$ days) and red symbols represent "persistent" clusters (greater than or equal to 3 of the past 4 days). Clusters feature clickable attributes so field managers can quickly identify which condors are associated with each cluster.

\section{Objective 7-Automating Alerts Indicating Transmitter Readiness and Condor Behavior}

Two types of alerts are generated as part of the daily map process. The following are examples of the format of alerts emailed to Complex staff the day after they occur:

- No transmission from the deployed transmitter during the past 7 days. Example of the alert message: "No transmission from condor 482 in the past 7 days."

- No movement of an individual bird for over 24 hours where nonmovement is defined as less than 100 meters between locations (refer to appendix 3). Example of the alert message: "Condor 107 has not moved from 2014-12-02 08:14 PST to 2014-12-03 13:21 PST." 
In addition to the alerts, the USFWS ensures that two VHF units are attached to each condor at all times. These VHF units are capable of transmitting a mortality signal and would be used to locate the carcass of a condor after a mortality signal was received. The MTI PTT units can also aid in the recovery of condors with the use of additional locator equipment.

\section{Objective 8-Managing Legacy and Current Data}

Legacy data are defined as unproofed Argos (Doppler) PTT data acquired from 2001 to 2008. These data will always be unsuitable for analysis due to transmitter-ID/condor-ID mismatches and not knowing dates birds were in captivity while collecting GPS locations. Attempts to make the data usable were deprioritized because the effort that would have been required was beyond the capacity of the Complex staff.

Legacy data are in contrast to proofed MTI GPS PTT unit data (GPS tag data 2005-13) and current MTI and CTT GSM/GPS data that are suitable for analysis and display. Coarse Doppler data are also collected from the PTT units but would only be used if GPS data sources failed. All current data will be made available to researchers and managers through Movebank and ScienceBase. ScienceBase is the only Web site that will maintain the FISMA-compliant archive. The legacy data in ScienceBase are currently only accessible to select Complex staff and USGS. The public has access only to proofed condor data through ScienceBase. Legacy data and unproofed data will be made available to the public through a request to the USFWS or through the FOIA process.

\section{Results}

This improved System became operational in October 2014 (fig. 3). Movebank worked with staff at CTT to allow their GPS data to stream into Movebank, and Movebank is willing to work with other GPS data providers interested in GPS data stream integration. From the USFWS user perspective, details of using and maintaining some components of this System are provided in the "GPS Data Management Manual" (Mendenhall, 2014). The USGS developed the software to provide a daily pull of data from Movebank for deployment of the daily map in KMZ format and email alerts that provide information for lack of data transmission and lack of bird movement. The USGS also developed a 3-month GPS data pull to archive the data in ScienceBase. Movebank and the USGS added the Pinnacles National Park and the Ventana Wildlife Society GPS data streams for condor locations to the System. Other California condor projects are encouraged to add their GPS data streams to this System to complete GPS location integration.

\section{Objective 1-Streaming Global Positioning System Data into Movebank}

The process for registering a project with Movebank and establishing a live feed is provided in the "GPS Data Management Manual" (steps 1-3 in Mendenhall, 2014). The process includes registering with Movebank, creating a project space in Movebank, and establishing the live GPS data feed. Location data not based on a live feed can also be uploaded to Movebank using a comma-separated values (CSV) file. Four projects were created for the central California population of condors: Pinnacles National Park Argos, Pinnacles National Park GSM/GPS, VWS Argos, and VWS GSM/GPS. One project was created for the southern California population of condors (Argos/GPS was discontinued): Complex GSM/GPS.

GSM/GPS data from both CTT and MTI transmitters and GPS data from MTI Argos transmitters (Pinnacles National Park and VWS) are currently streaming into Movebank. On November 19, 2013, the first MTI GSM/GPS transmitter was deployed on a condor and complete datasets were 
received. The first CTT prototype number 1 was tested on a condor on September 18, 2013, and the prototype number 2 (final design) was first tested on a condor on November 13, 2013. Eight days were required for CTT to transition from testing prototype number 1 to having a fully developed prototype number 2.

The Complex discontinued using Argos/GPS because of the cost (table 1) and the more limited data content (appendix 2) and is now only using CTT and MTI GSM/GPS transmitters. The decreased costs and increased data content realized by switching from Argos/GPS PTT units to GSM/GPS systems are significant. The cost difference between an Argos/GPS PTT unit and a GSM/GPS unit is most significant concerning monthly data fees with GSM data transmission costing less than one-third the cost of Argos/GPS PTT transmission. Reported accuracy is higher for GSM units with the added benefit that location records include associated vertical dilution of precision (VDOP) and horizontal dilution of precision (HDOP) values (appendix 2). The lower cost and higher resolution GSM/GPS data can better reflect actual flight paths and ground locations, helping field managers understand where condors fly in relation to obstacles such as wind turbines and where condors spend time on the ground for feeding or roosting. Additionally, access to higher resolution location data will permit finer scale spatial analyses, the results of which could guide future management actions.

Argos systems were providing 10-15 locations per transmitter per day, whereas the GSM systems are providing several hundred locations per transmitter per day depending on the settings for a transmitter. The increased number of GSM GPS data locations required new methods for analyzing and interpreting the data. The development of the daily map (showing clusters of condors) and various alerts (nonmovement and transmitters not transmitting) is an excellent tool to help simplify the interpretation. The GSM/GPS transmitters used in this project also record the VDOP and HDOP, which are an indication of the accuracy of each location fix. DOP values are unitless and lower values indicate better satellite geometry and greater accuracy.

Table 1. The cost comparison (2014) of three wildlife tracking global positioning system (GPS) data providers used during this project. The unit cost is for a single GPS transmitter. The service cost is summed for a 3-year period assuming a 3-year operational lifetime.

[GPS, global positioning system; MTI, Microwave Telemetry, Inc. ${ }^{\text {TM} ; ~ G S M, ~ G l o b a l ~ S y s t e m ~ f o r ~ M o b i l e ~ C o m m u n i c a t i o n ; ~}$ CTT, Cellular Tracking Technologies, LLCTM; UHF, ultra high frequency; PTT, Platform Transmitter Terminal]

\begin{tabular}{|c|c|c|c|}
\hline \multicolumn{4}{|c|}{ GPS Data Providers Pricing Table with Three Years of Service } \\
\hline Vendor & Unit Cost & Service Cost & Total Cost \\
\hline MTI GPS Argos & $1,2 \$ 3,950$ & $\$ 3,503$ & $\$ 7,453$ \\
\hline MTI GPS GSM & ${ }^{2} \$ 3,950$ & $\$ 900$ & $\$ 4,850$ \\
\hline CTT GPS GSM & ${ }^{3} \$ 3,000$ & $\$ 1,100$ & $\$ 4,100$ \\
\hline
\end{tabular}

\footnotetext{
${ }^{1}$ The units cost $\$ 4,150$ with the UHF GroundTrack feature, which was not used in this project.

${ }^{2}$ A $\$ 200$ discount is available when 10-24 PTTs or GSM/GPS units are purchased and a \$400 discount is available with 25 or more units are purchased.

${ }^{3}$ CTT-1000a Series units include a 5\% discount for 10-14 units, a $7.5 \%$ discount for $15-19$ units, and a $10 \%$ discount for 20 or more units.
} 


\section{Objective 2-Associating Transmitter-Identifier with Condor-Identifier}

The Movebank Deployment Manager allows the user to associate transmitter-IDs with condorIDs and is fully operational. The deployment information can be entered using the Web-based user interface where the user enters information about each animal (condor-ID) and the corresponding transmitter-ID, or a comma-delimited (CSV) file can be uploaded that contains the required information. The deployment database is stored in Movebank and on the USFWS server (fig. 3). This process is described in detail by Mendenhall (2014).

\section{Objective 3-Proofing Global Positioning System Data}

Automated and manual processes in Movebank are used to proof GPS data. Both processes involve flagging data but not deleting any location records. Automated proofing is a function within Movebank employing various filters. Manual data proofing is accomplished within Movebank by using the Movebank Event Editor interface. Details of this process are provided by task 3 in Mendenhall (2014). The original proofing technique, prior to having the Movebank Event Editor, required an entire day to proof 3 months of data that consisted of approximately 16,000 Argos/GPS locations. Using the Movebank Event Editor interface, only 3 hours is required to proof 3 months of GPS data that consist of approximately 100,000 GSM/GPS locations. This resulted in approximately 60 percent less time required to process more than six times as many GPS locations. Using this technique, the USFWS met their proofing needs and helped Movebank design and test the addition of new features. The DAF (Douglas and others, 2012) is no longer needed because of the new capabilities built into Movebank.

\section{Objective 4-Associating Environmental Data with Global Positioning System Tracking Data}

The USFWS has chosen not to utilize Env-DATA at this time although the system is fully operational within Movebank. The Env-DATA provides an online view of tracks and locations and can provide a live map of "celebrity bird" tracks in the client's or their collaborators' Web sites through a Web Feature Service.

The Movebank portal provides users with a visualization system that displays the track data on Google Maps ${ }^{\mathrm{TM}}$ with either a Google Maps ${ }^{\mathrm{TM}}$ view or a satellite view (fig. 12). Track data can be viewed as points, lines, vectors, or as a density map, and the user can control the dot size. A subset of either transmitters or animals can be selected to view in addition to being able to view all track data. The map views and tabular views can also be combined, and locations can be selected directly from the map or the table. 


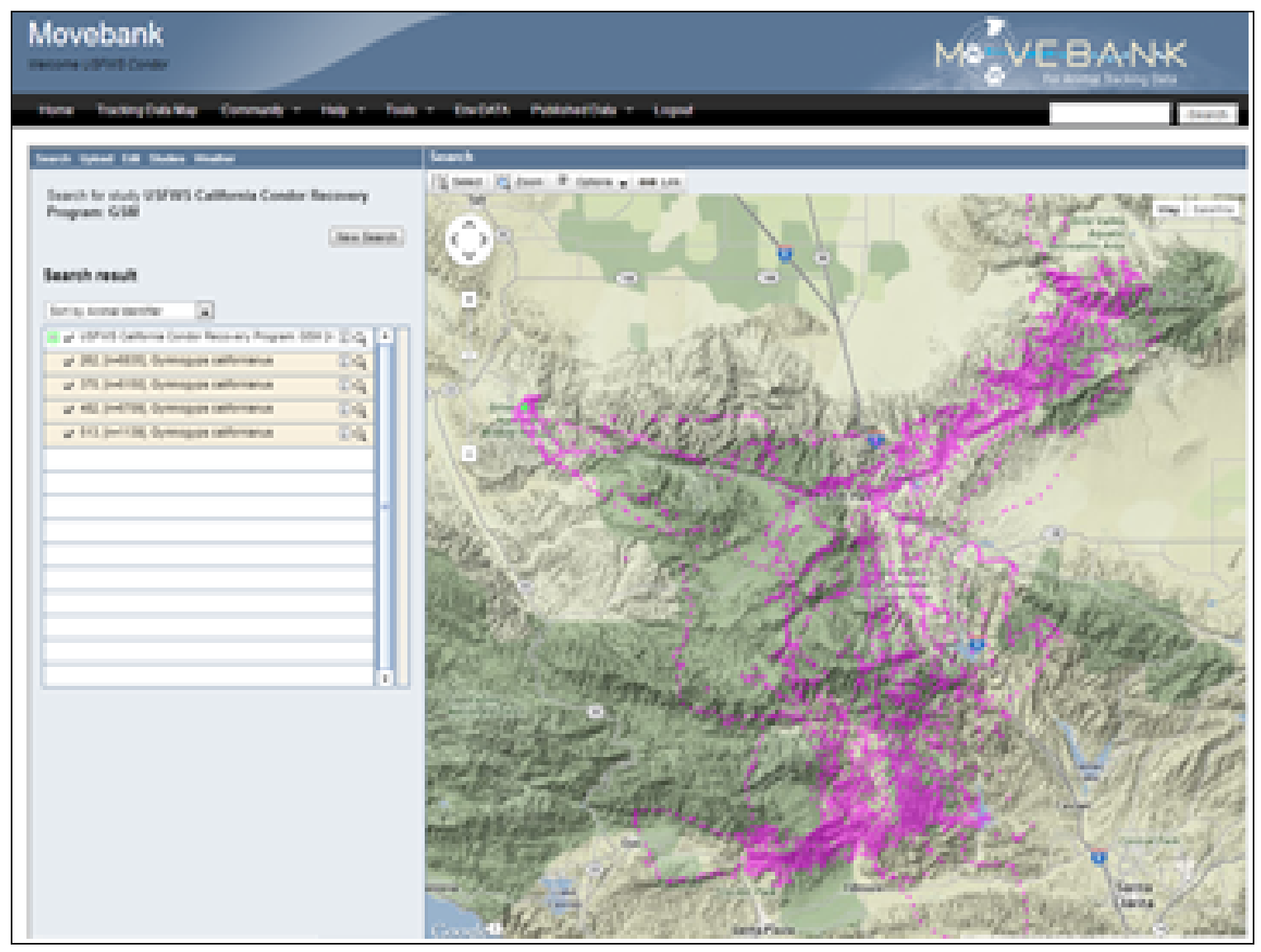

Figure 12. A Movebank data interface map showing a sample of California condor track locations (pink dots; image courtesy of Movebank).

Visualization of data annotated with Env-DATA can be performed using the visualization tool provided by Movebank in the "tools" interface (https://www.movebank.org/panel_software). This JAVA software tool allows coexploration of track and annotated environmental data, and provides visualization of three annotated data variables simultaneously by scaling the dot color, line color, and line width. The Env-DATA allows the user to browse the data and produce an animation utilizing the time variable (fig. 13). 


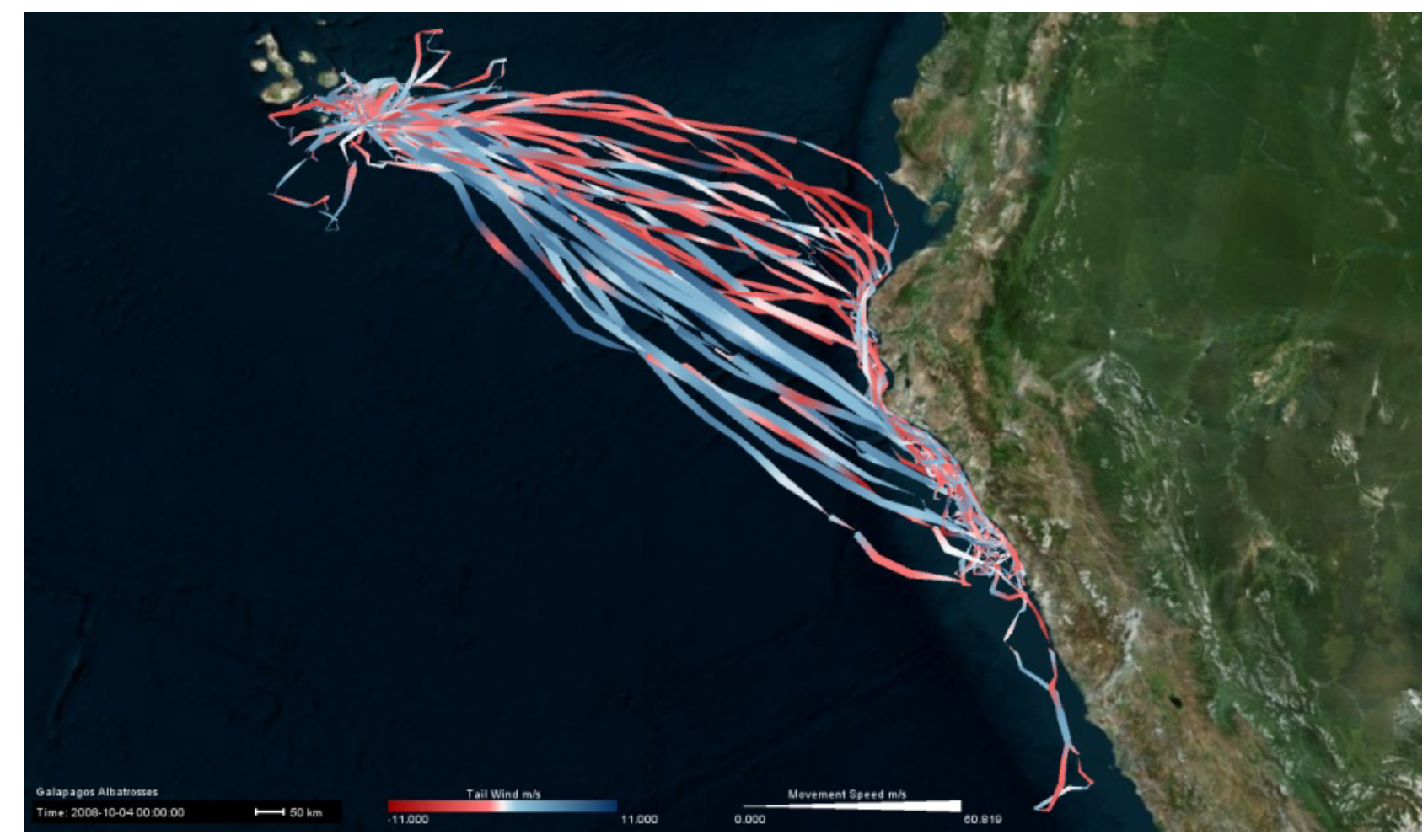

Figure 13. An example of the Movebank Environmental Data Automated Track Annotation System (Env-DATA) visualization tool illustrating Galapagos Albatross data annotated with tailwind speed (red represents a negative tailwind and blue a positive tailwind). Prevailing winds are east to west (right to left). The Galapagos Albatross expend energy flying into the wind over long distances in order to obtain critical food resources along the mainland coast (Xavier and Dodge, 2014).

Movebank also provides the tools to create a specialized Web page where location data are streaming live and presented on a map with user-defined graphics. This feature was not implemented by any of the condor tracking projects.

\section{Objective 5-Moving Data from Movebank to ScienceBase for Archive}

The CCMAP automatically pulls condor data from Movebank on a quarterly basis for archive. The CCMAP is a management portal for California condor location data that (1) produces the daily map of condor locations (locations pulled from Movebank, converted to KML, and emailed to the contact list); (2) pulls all condor data from Movebank each quarter for archive; (3) checks daily condor transmissions to identify lack of transmission and potential lack of movement issues and sends alerts, as appropriate, to the contact list; and (4) allows administrators to edit the contact list. Additional functionality may be added in the future.

Both proofed and unproofed data are archived each quarter. At the end of each quarter, the following month is reserved for proofing and the archive occurs during the first Sunday of the next month. For example, the first quarter is January through March. April is reserved for proofing and archiving occurs during the first Sunday in May. If the records for a given quarter are not proofed by the archival date, only unproofed records will be archived. There is no protocol for re-archiving data proofed after the initial archive. 
Metadata elements for all GPS data are defined in two parts in section 3 of Mendenhall (2014). The first section defines Reference and Deployment Metadata with subcategories Animals, Deployments, and GPS Units. The second section defines GPS Location Metadata with subcategories Esri $^{\text {TM }}$ Shapefile Fields (from the ScienceBase archive) and CSV Fields (from the ScienceBase archive).

\section{Objective 6-Automating the Daily Map}

The daily map is generated automatically in CCMAP from unproofed data pulled from Movebank and emailed to designated users in KMZ format (appendix 3). Unique daily maps are emailed to the Complex, Pinnacles National Park, and the VWS. The Complex Supervisory Condor Biologist uses CCMAP to control who receives the daily map for the southern and central California condor groups.

The user can toggle approximate flight paths (lines connecting consecutive points), stationary locations (GPS location records with speed less than or equal to $10 \mathrm{~km} / \mathrm{h}$ ), moving locations, daytime locations, nighttime locations, all locations associated with adults (greater than 6 years old), and all locations associated with juveniles. Once a layer is toggled on, the user can adjust the Google Earth ${ }^{\mathrm{TM}}$ time slider bar to view data for any period within the 1-week time frame. Locations and flight paths are color-coded by individual condor with symbology reflecting stationary (square) or moving (circle) activity and feature clickable attributes. The default settings upon opening show stationary daytime locations and flight paths so field managers can easily ascertain areas of interest. Daytime stationary locations are associated with "ground" activity meaning perching on trees, resting on the ground, feeding, perching on human-made structures, or sickness or trauma. Field managers identified these activities as of most interest for guiding day-to-day management activities. Flight paths are approximate but can quickly alert a field manager to a possible flight near or over a wind turbine or other area of interest.

\section{Objective 7-Automating Alerts Indicating Transmitter Readiness and Condor Behavior}

CCMAP automatically checks daily data transmissions to identify alert issues and sends an email to individuals in the Contact List (appendix 3). The four projects for the central California condor population (refer to Objective 1 in the "Results" section) receive a consolidated email with alerts. The single project for the southern California condor population receives one email with alerts. If there are no alerts for a given day, no email is sent. The following is an actual email showing alerts for the central California condor population:

Alerts for argos-pinn condor transmissions

Condor 317 has not moved from 2014-12-02 13:00 PST to 2014-12-04 14:00 PST

Condor 317 has not moved from 2014-12-04 17:00 PST to 2014-12-06 13:00 PST

Condor 438 has not moved from 2014-12-02 07:00 PST to 2014-12-03 10:00 PST

Condor 438 has not moved from 2014-12-04 16:00 PST to 2014-12-06 10:00 PST

Condor 550 has not moved from 2014-12-02 13:00 PST to 2014-12-04 10:00 PST

Condor 550 has not moved from 2014-12-04 18:00 PST to 2014-12-06 13:00 PST

Condor 626 has not moved from 2014-12-02 07:00 PST to 2014-12-03 08:00 PST

Condor 626 has not moved from 2014-12-03 15:00 PST to 2014-12-05 08:00 PST

Alerts for gsm-pinn condor transmissions

Condor 564 has not moved from 2014-12-02 06:37 PST to 2014-12-03 07:40 PST

Alerts for argos-vws condor transmissions 
Condor 236 has not moved from 2014-12-04 14:00 PST to 2014-12-06 13:00 PST

Condor 375 has not moved from 2014-12-02 14:00 PST to 2014-12-04 14:00 PST

Condor 375 has not moved from 2014-12-04 15:00 PST to 2014-12-06 12:00 PST

Condor 168 has not moved from 2014-12-03 12:00 PST to 2014-12-04 14:00 PST

Alerts for gsm-vws condor transmissions

No transmission from condor 567 in the past 7 days

No transmission from condor 646 in the past 7 days

No transmission from condor 665 in the past 7 days

If a GPS unit has not moved in 24 hours, CCMAP generates an alert email that indicates the condor-ID and dates of perceived nonmovement. The alerts are designed to capture malfunctioning GPS units, detached GPS units, and condor mortalities; however, the alert algorithm also captures some atypical GPS behavior such as when a unit fails to collect location data for a period but then transmits. These "false positives" are quickly eliminated from the field manager's list of concerns by accessing the condor data in the map to ensure the condor has in fact moved.

\section{Objective 8-Managing Legacy and Current Data}

Legacy and current data are stored in Movebank and ScienceBase. The final repository in ScienceBase allows access to the entire proofed condor location dataset stored in a format that is consistent across field sites. The data are proofed to a high standard by experts at each field site, and each attribute is defined, which is advantageous for researchers interested in doing species distribution modeling and other retrospective analyses.

The USFWS does not expect that anyone will need to access the legacy data (unproofed satellite Doppler tag data from 2001 to 2008) since it is not possible to accurately associate the transmitter-ID with the condor-ID, and because the Doppler data have low positional accuracy. The USFWS, National Park Service (NPS), and VWS users can access legacy and current data through Movebank and ScienceBase. The public can access current data at ScienceBase and legacy data can be accessed through a request to the USFWS or the FOIA process.

Primary data management tasks described by Mendenhall (2014) include:

- Maintain an accurate, up-to-date deployment log.

- Add additional GPS transmitters to the Movebank live feed as needed.

- Proof GPS location data on a quarterly basis.

- Download the Deployment Log on a quarterly basis for in-house archive.

- Maintain a database of actions taken for the previous four tasks.

- Maintain the daily map/alerts distribution email list.

Movebank is dedicated to maintaining and enhancing its services (appendix 4 [Martin Wikelski, Max Planck Institute for Ornithology, written commun., 2014]) and providing security for user databases. The USGS will maintain the ScienceBase Project, which will continue to pull data from Movebank automatically, generate and email the daily map and alerts (CCMAP), and provide an FISMA-compliant archive for all condor projects. Both CTT and MTI use a server system with cloud/mirroring to mitigate risks of data loss and provide permanent storage. 


\section{Accessing California Condor Project Data in ScienceBase}

The California condor data are stored in ScienceBase under the Landscape Conservation Management and Analysis Portal (LC MAP) community. The LC MAP is a ScienceBase portal developed for the U.S. Fish and Wildlife Service. The data are accessed at ScienceBase (2015).

The home page lists the datasets from all condor projects and the California Condor Metadata. Clicking on a header in the format DataType-Project-Date opens a data file page with access to the data files. For example, gsm-sCal-2014-12-29 represents GSM/GPS data (gsm) for the southern California USFWS project (sCal) for the archive date ending December 29, 2014 (2014-12-29).

The data file page displays the California condor GPS point locations on a background map. It may be necessary to use the scroll bar on the right side of the window to view the data listings at the bottom where the following naming conventions will be listed.

\section{Global Positioning System Data Source Naming Conventions}

- gsm: GPS data acquired through the Global System for Mobile Communication (the cellular network).

- argos: GPS data acquired through the Argos satellite system.

\section{Global Positioning System Project Naming Conventions}

- pinn: National Park Service, Pinnacles National Park Project

- vws: Ventana Wildlife Society Project

- $\quad$ SCal: U.S. Fish and Wildlife Service Southern California Project

On the home page, the user can click on "California Condor Metadata" to access the file "CACO_Metadata.xml." This file can be opened or saved to the user's system and contains the California Condor Project metadata.

\section{Accessing the Data-Example}

1. Data for download: Clicking on a zip file such as "gsm-sCal 2014-12-29.zip" allows the user to "open" or "save" the file to their system and extract the contents. The zip file contains files similar to the following.

Deployment.csv—Contents are deployment data correlating transmitter-ID (tag_id) with the condor-ID (individual_id).

Event_2014-09-30_to_2014-12-29.csv-This file contains the complete GPS data archive for the dates specified and supersedes the shapefile that can also be downloaded (see below). The date format for the field named "timestamp" is YYYY-MM-DD. In Microsoft Excel"TM, you must set the date format to yyyy-mm-dd hh:mm:ss.ssss to be able to view the date correctly. To do this, highlight the "timestamp" column in Microsoft Excel ${ }^{\mathrm{TM}}$ and right click and select "Format Cells." In the Number tab click on "Custom." After "Type" type in "yyyy-mm-dd hh:mm:ss.ssss." Then, click "OK" and the date/time will be displayed correctly in Microsoft Excel"TM. As a final step, the user may need to sort by "timestamp" using the option to "Expand the selection" to all fields.

Individual.csv - Information about each bird.

Sensor.csv-Information about the transmitters.

Study.csv-Information about the project.

Tag.csv-Information about the transmitters.

Tag_type.csv_-Information for Argos tag. 
Note: The CSV files on ScienceBase are formatted to fit the Movebank internal database structure only and are not intended for use other than for archival to replicate the Movebank study should it ever dissolve. Some fields will not make sense outside of the Movebank database structure. The user of these CSV files should reference the Movebank attribute dictionary to understand each field. This disclaimer is reported in the metadata on the ScienceBase archive Web site (modified from Mendenhall, 2014).

2. Shapefile for download: Under the "Resources" heading, next to the "Extension" heading, there is listed, for example, "gsm-sCal 2014-12-29." If the user clicks on this, the system zips together all the components of the shapefile listed below this heading and allows the user to save the zipped file to their system. When the zip file has been built, a window appears at the bottom of the page. By clicking on the down arrow next to the word "Save" the user can save the file to any directory on their system. When the user unzips the file, they will have all the components of the shapefile (.shp, .dbf, .shx, and .prj files) ready to view in Esri ArcGISTM or other suitable software. The shapefile coordinates are in WGS84 Geographic Latitude/Longitude in decimal degrees using the datum of the World Geodetic System 1984. There are no metadata at the shapefile level beyond the start and end dates that are visible when the user drills down into the item in ScienceBase (refer to Objective 5 in the "Results" section). The product owner is responsible for providing additional metadata for all components of the project that are stored in the "California Condor Metadata" item at the top level of the Active Data folder.

\section{Discussion}

The Pinnacles National Park and the Ventana Wildlife Society have implemented this System with great success. The central California condor population is now fully integrated into the daily map, alert system, and ScienceBase data repository. The ease with which the System was applied to California partner projects makes the idea of applying the system to partners outside California appealing.

\section{Utility of the System for Other Wildlife Tracking Efforts}

This System, although in its infancy, is an improved GPS data capture, delivery, archive, and management system, which includes improved quality and quantity of GPS data and reduced costs. The System may work with other animal movement tracking studies depending on several factors:

- GSM is relatively new technology and is reliant on cellular coverage throughout the project area. Since cell tower location data are proprietary, field managers have to make the assumption that GSM technology will work in a given area based on consultation with the cellular coverage provider. When CTT and MTI GSM/GPS transmitters are outside cellular coverage, they store fixes until they regain a cellular connection (refer to appendix 2). The GSM/GPS data transmission has the advantage of being able to stream directly into Movebank and on through the remainder of the system to the archive. Automating the GSM data stream into Movebank is an advantage over non-GSM data, but any other data source can be added to Movebank manually.

- The environmental components of a study location may affect the utility of using GSM/GPS for animal tracking. The transmitter manufacturers should be incorporated into the life cycle of the project to optimize the available technologies, deal with unforeseen issues during the project life, and provide technological enhancements as they become available. 
- Non-GSM data sources can be manually added to Movebank, but this requires one more step by the user that could delay data flow through the system and could lead to lost data. Rigorous quality assurance/quality control procedures would be required to ensure timely and accurate data flow through the system. Manually adding non-GSM data into Movebank may be necessary at the start of a new project in order to ensure all project data are in the new system.

- This project demonstrated that switching to GSM/GPS tracking can reduce costs significantly for wildlife tracking (table 1). The USFWS California condor program will save more than \$104,000 during 3 years simply through the replacement of MTI Argos/GPS PTT hardware and service costs $(n=40)$ with the lower hardware and service costs of GSM/GPS vendors such as CTT or MTI.

- Project design should incorporate planning and funding to account for the loss of transmitters. Depending on the species being studied and other factors, it may be advisable to implement a public relations program to educate the public about the project and encourage the return of equipment (Tomkiewicz and others, 2010).

- The automated nature of the System provides next-day notification of critical animal tracking events. In cases where GPS data must be manually uploaded to Movebank, timely alerts and a daily map may not be possible.

- We estimate that approximately 6 weeks of a programmer's time would be required to incorporate a completely new data capture project into this system. The work would include setting up the data stream into Movebank and culminating with the archive files residing in ScienceBase. This would apply to projects for other species where the Movebank fields and symbology rules would be different from the current condor project. The estimate includes 2 weeks each for setting up the archive, setting up the daily map, and working with clients on various iterations during development. The total estimate could drop to 2 weeks for additional condor projects assuming the same internal structure in Movebank and the same symbology rules for the daily map.

- The USFWS staff studying the southern California condor population decided it was unnecessary to obtain nighttime fixes because condors tend to be stationary at night. At the request of the USFWS, CTT units were not set to collect nighttime fixes, whereas MTI units were set to collect a nighttime fix once per hour. Nighttime fixes may be desirable to help locate a nontransmitting unit since every additional fix can aid in establishing an initial search area (Lance Jordan, Microwave Telemetry, Inc. ${ }^{\mathrm{TM}}$, written commun., 2015). Microwave Telemetry, Inc. ${ }^{\text {TM }}$ recommends using Argos/GPS PTT units with nighttime fixes and Ground Track ${ }^{\text {TM }}$ capability when knowledge of mortality is mission-critical and for retrieving units that have stopped transmitting a GPS signal (Lance Jordan, Microwave Telemetry, Inc. ${ }^{\text {TM }}$, written commun., 2015). Expensive aerial surveys may be required to locate a nontransmitting unit whether the unit is Ground Track ${ }^{\mathrm{TM}}$ or VHF-enabled, but the initial search effort can be minimized by having the units transmit daytime and nighttime GPS fixes. The MTI Ground Track $^{\text {TM }}$ option costs an additional \$200 per unit. Cellular Tracking Technologies, LLC ${ }^{\text {TM }}$ can provide VHF capability with their GSM/GPS transmitters for an additional \$300 per unit. Transmitter specifications and costs mentioned here may soon become obsolete, and the potential user is advised to contact each manufacturer for current information. All condors in the southern California population are fitted with two VHF transmitters (independent of the GPS transmitter) regardless of the type of GPS transmitter used.

- Both GPS and VHF transmitters can affect animal behavior, reproduction success, and ultimately survival (Tomkiewicz and others, 2010). Careful planning and pre-project 
experimentation is advised on a subset of an animal population before implementing a full-scale animal tracking system (Tomkiewicz and others, 2010).

- Newly developed technological components of an animal tracking project should be tested on a subset of a population before implementing the full-scale project (Tomkiewicz and others, 2010).

- The GPS specifications, capabilities, and costs presented in this report will soon be obsolete. Anyone planning an animal tracking project utilizing GSM/GPS systems should consult with manufacturers before committing to a system.

\section{The Data Life Cycle Process}

A GPS data capture and delivery system will not be effective and efficient without properly addressing each component of the data life cycle (fig. 14). The data life cycle begins with planning and continues by cycling back through planning while incorporating quality assurance/quality control at each stage. The data life cycle is cyclical rather than linear. It is an ongoing process.

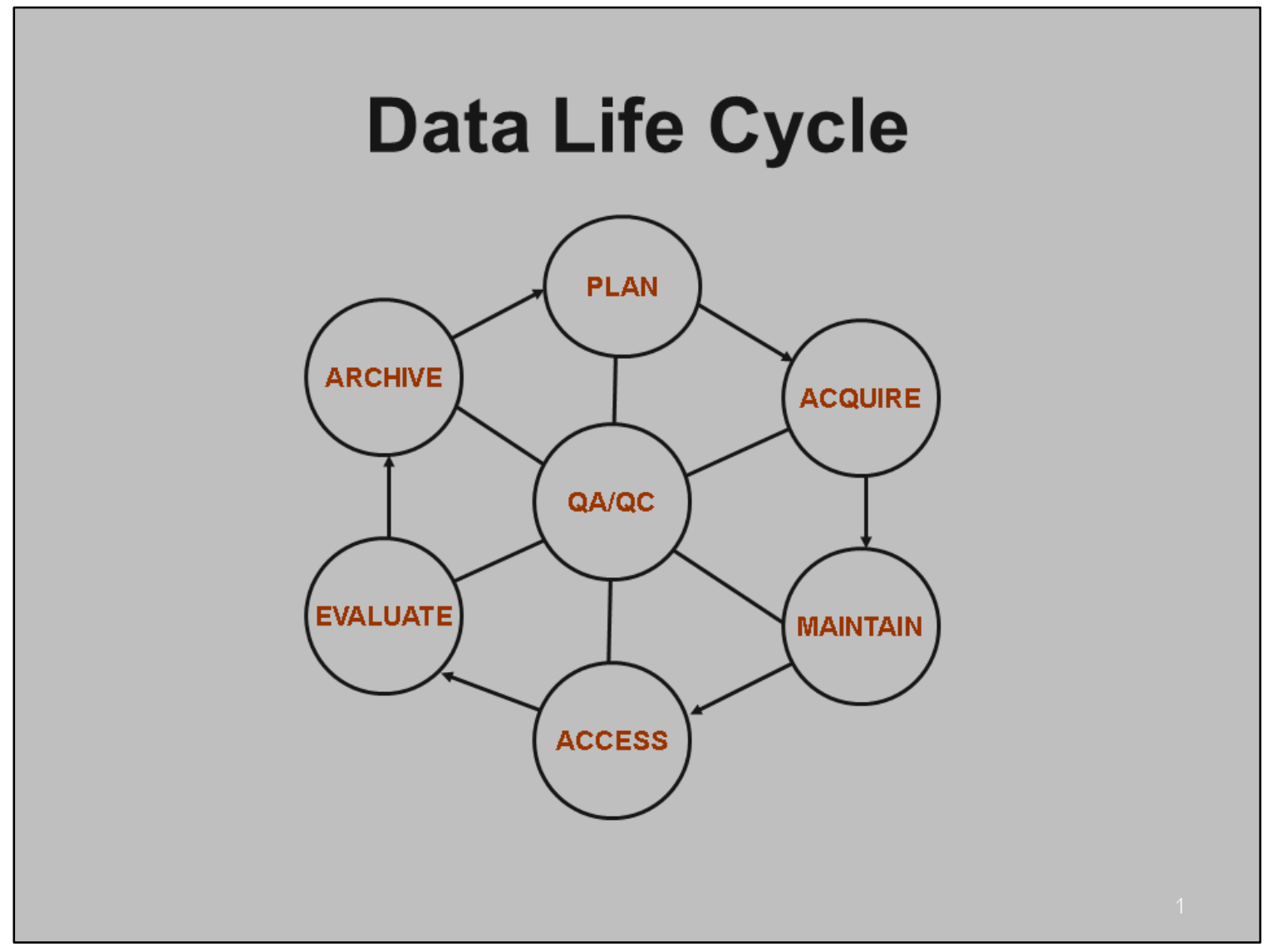

Figure 14. The data life cycle (Image courtesy of U.S. Fish and Wildlife Service). [QA/QC, quality assurance/quality control]

The GPS data capture and delivery system developed during this project is designed to incorporate each component of the data life cycle. This design will result in reduced costs and risks to 
the Condor Recovery Program while ensuring higher quality program performance. The project design addressed the following components.

\section{Planning}

Establishing goals and objectives early in an interorganizational collaborative process was critical. The process began with a carefully conceived proposal and evolved through emails, conference calls, and eventually a project planning meeting in Ventura, Calif. The planning meeting included representatives from the USFWS, USGS, Movebank, and CTT with the expertise to address the structure and limitations of the existing data management model and develop an improved system. Iterative planning continued after the initial meeting with the development and subsequent refinement of specific project goals and objectives and eventually implementation. The participants developed a plan focused on ensuring long-term data preservation, simplified user interface and access to data, lowered cost of data acquisition and management, delivery of timely data to end users, and streamlined data access for external data requestors.

\section{Acquire}

The lower cost and greater frequency of GSM/GPS data compared to Argos/GPS data resulted in discontinuing Argos/GPS data acquisition by the Complex (refer to table 1; appendix 2). A significant potential drawback to the GSM system is the unavailability of cellular coverage for transferring GPS data from the transmitters to the data provider's servers. We reviewed cellular coverage during the planning process and determined it to be sufficient because (1) the size and distribution of cellular "holes" were acceptable, (2) there is greater cell coverage at the altitude of flying condors, and (3) when condors are on the ground (or flying) and unable to transmit over the cellular network, the data can be stored until cellular coverage is regained (refer to the "Design, Testing, and Evolution of Cellular Tracking Technologies' Prototype Transmitters" section). Future planning may include research to further miniaturize GPS transmitters, testing to determine an optimal GPS sampling rate based on specific study objectives, and the acquisition of physiological attributes through the GSM.

Maintain

Maintenance of the GPS data is facilitated by having it stored permanently by CTT, MTI, Movebank, and ScienceBase. Federal employees using ScienceBase will fulfill much of their data stewardship responsibilities once tracking data have been uploaded to ScienceBase and documented, ensuring long-term preservation, discoverability, and use of this important data resource. A critical component of this project was to ensure the proper correlation of transmitter-ID with the correct condorID since transmitters occasionally move between condors. This critical task is performed using the Movebank Deployment Manager. The Movebank Event Editor performs data proofing, where erroneous data records are flagged but not deleted. This proofing guarantees the permanent retention of all GPS data.

\section{Access}

Access to the GPS data is possible through both Movebank and ScienceBase. In both cases, the data owners determine access options. Access can be granted for viewing or downloading data or both. Future planning for the data life cycle may include making the data accessible through entities such as Data Basin (http://databasin.org/), ServCat (http://www.fws.gov/Refuges/NaturalResourcePC/IandM/serviceCatalog.html), or ECOS 
(http://ecos.fws.gov/ecos/home.action). Currently, the public only has access to the data through ScienceBase. The public can obtain legacy or unproofed data by requesting them from the USFWS or by following the process established by the FOIA (5 U.S.C. $\S 552$ ).

\section{Evaluate}

Data evaluation should be continuous to ensure that data meet the requirements of the program, the data frequency and quality are sufficient, erroneous data are corrected, and users are notified of any data quality issues. Data evaluation is a function of the Movebank Deployment Manager, the Movebank Event Editor, and the automated daily map and alerts provided by the USGS through ScienceBase/CCMAP. Metadata for their respective products are available from CTT, MTI, Movebank, ScienceBase, and Mendenhall (2014).

Archive

An automated archive system has been implemented in ScienceBase. ScienceBase ensures a permanent archive with the data also stored in the USGS Cloud Hosting Solution. Metadata are included with the archive. It is the responsibility of the USFWS to archive the condor GPS data with the National Archives and Records Administration.

\section{Quality Assurance/Quality Control}

Quality assurance and quality control are vital for each stage of the data life cycle and will be the primary responsibility of the USFWS Complex. Movebank and ScienceBase have quality assurance/quality control processes and will be cooperating fully with the USFWS.

\section{Movebank's Long-Term Project Management Status}

The Movebank global database operates under the umbrella of the Max Planck Institute for Ornithology (MPIO) and expects to remain operational indefinitely (appendix 4). The MPIO policy states that it will maintain Movebank as a database for animal movement data without cost to the users while maintaining the data format, data storage policy, and privacy policy in addition to providing database enhancements (appendix 4). Movebank has no immediate plans to change their data policy, which states that the data owners remain in full control, and that data will only be made available to designated entities or the public with the consent of the data owners. Nor does Movebank have plans to change the data storage format or database metadata. Data owners may also continue to add new attributes to existing data. Track metadata (timestamp, location, tag ID, animal ID, and deployment) will not change.

Movebank is working on several key improvements to their Web site. First, the scaling of the data display on the map will be enhanced so that large datasets will load quickly. Second, a data viewer similar to the visualization/animation tool will be added as a map option (Xavier and Dodge, 2014). Third, Movebank is testing a new "smart" tag that will allow new analysis approaches to infer wind and uplift from the new tag measurements. Movebank will offer this capability to users who acquire the new tags. Lastly, Movebank has applied for a grant from the National Aeronautics and Space Administration to develop a forecast and movement modeling tool. 


\section{Suggestions}

This report is meant to be a "how to" resource specifically for biologists and researchers who are participating in wildlife tracking efforts. Although the report targets the southern California population of the California condor, the GPS data management scheme provided should be applicable to other wildlife tracking efforts. The use of Movebank and ScienceBase is encouraged because they can be used to efficiently organize and manage GPS tracking data for any species or project. Responsibility resides with animal tracking project staff to accurately manage the association between transmitters and individual target animals, and to proof the data prior to archiving the data in order to maintain data integrity. The following suggestions pertain specifically to the various California condor programs but also to the development of future animal tracking efforts.

1. Re-evaluate the improved GPS data capture, delivery, and archive system described in this report annually with reference to the data life cycle. For example, GPS technology is constantly advancing, and new animal tracking technologies, such as those utilizing the Earth's magnetic field and quantum positioning (Marks, 2014), may eventually compete with GPS.

2. Ensure the 3 months of data to be archived are proofed a few days prior to the scheduled automatic archive, otherwise the data in that archive file will never be recorded as proofed. The data recorded between when the records are proofed and when they are archived can be proofed prior to the next automatic archive and captured in the 1-month overlap between archives. If this process is followed, at least one version of each record will be recorded as proofed in at least one archive file.

3. Encourage all organizations with California condor field tracking responsibilities to tie into this system so that all California condor tracking data are stored in both Movebank and ScienceBase while taking advantage of their respective value-added resources.

4. Expand use of GSM/GPS systems and reduce dependence on the Argos/GPS.

5. Encourage the development of miniaturized solar-powered transmitters with battery capacity capable of real-time transmissions.

6. Continue to work with Movebank, which is a valuable partner for ingesting, managing, enhancing, visualizing, storing, and disseminating animal tracking data. Movebank also acts as a resource for identifying other animal tracking projects for possible collaboration.

7. Monitor the resources of ScienceBase/CCMAP for automated archive, automated daily map, and various automated alerts for updates as required by the Condor Recovery Program.

8. Enhance ScienceBase to make it easier for other wildlife tracking efforts to utilize this system's capabilities and reduce costs for archiving and delivery of GPS tracking data.

9. Investigate additional cloud-based alternatives for viewing and analyzing GPS location data. Several vendors have expressed interest and are actively developing spatial-temporal cloudbased data visualization and analysis systems.

\section{Summary}

At the request of the U.S. Fish and Wildlife Service (USFWS) staff in the Pacific Southwest Region and at the Hopper Mountain National Wildlife Refuge Complex, the U.S. Geological Survey (USGS) provided technical assistance to improve the Global Positioning System Data Acquisition, Management, and Archive System in support of the California Condor Recovery Program. Daily operational monitoring and management of Gymnogyps californianus (California condor) and long-term research require global positioning system (GPS) tracking data for individual condors. The USGS obtained funding through the Science Support Program to transition GPS data transmission technology 
from the Argos ${ }^{\mathrm{TM}}$ system to the Global System for Mobile Communication (GSM ${ }^{\mathrm{TM}}$ ). Eight objectives were achieved. First, USFWS staff worked with two private companies to design, develop, and fit condors with GSM ${ }^{\mathrm{TM}} / \mathrm{GPS}$ transmitters and establish GPS data streams into Movebank. Second, using a Web-based user interface the Movebank Deployment Manager associated transmitter identifiers with the condor identifiers, which reduced the probability of an identifier mismatch. Third, automated and manual processes in Movebank were used to proof the GPS data by flagging, not deleting, erroneous records. This preserved all GPS records for historical archive while making valid records available for management and research. Fourth, although it was not used in this project, Movebank provided the Environmental Data Automated Track Annotation System (Env-DATA), which allows online viewing of GPS tracks and locations and the capability for clients to present a live map of "celebrity bird" tracks on the Web site of the client or their collaborators through a Web Feature Service. Fifth, the California Condor Management and Analysis Portal (CCMAP) developed by the USGS automatically pulls GPS condor data from Movebank on a quarterly basis for permanent archive in the USGS ScienceBase, which is compliant with the Federal Information Security Management Act of 2002. Sixth, the CCMAP automatically generates a daily map for managers displaying flight paths and several behavioral features of the individual condors. The map can be displayed in Google Earth ${ }^{\mathrm{TM}}$ with color coding for individual condors and behavioral traits. Seventh, CCMAP automatically checks daily data transmissions to identify alert issues (nonmovement in 24 hours, malfunctioning GPS units, detached GPS units, condor mortalities) and sends email to individuals in the Contact List maintained by USFWS staff. Last, legacy and current data are stored in Movebank and permanently archived in the USGS ScienceBase. Managers and researchers can access the data through Movebank or ScienceBase, whereas the public can access non-legacy data through ScienceBase. The system described here is based on a seven part data life cycle, which should be reviewed periodically to ensure the system's long-term viability. Nine suggestions are provided that pertain specifically to the various California condor programs but also to the development of future animal tracking efforts.

As a result of the project's success, Pinnacles National Park and the Ventana Wildlife Society California condor programs became partners and adopted this data management and archive system. This GPS tracking data management model and workflow should be applicable and beneficial to other wildlife tracking programs.

\section{Acknowledgments}

The authors thank Joseph Brandt for his contributions to developing the Global Positioning System (GPS) Data Capture, Delivery, and Archive System; field testing GPS transmitter housings and attachments; and suggestions for facilitating public access to the data. Sarah Davidson at Movebank assisted with establishing the Movebank account. Drs. Todd Katzner and Michael Lanzone at Cellular Tracking Technologies, LLC ${ }^{\text {TM }}$ contributed to the timely design changes for the GPS housing and to transmitter deployments. Lance Jordan at Microwave Telemetry, Inc. ${ }^{\mathrm{TM}}$ reviewed the final document and provided valuable comments. Rachel Wolstenholme at Pinnacles National Park and Pek Pum at the San Diego National Wildlife Refuge Complex assisted with development of the study area map.

\section{References Cited}

CTIA, 2015, CTIA everything wireless: accessed December 9, 2015, at http://www.ctia.org/.

Dee, D.P., Uppala, S.M., Simmons, A.J., Berrisford, P., Poli, P., Kobayashi, S., Andrae, U., Balmaseda, M.A., Balsamo, G., Bauer, P., Bechtold, P., Beljaars, A.C.M., van de Berg, L., Bidlot, J., Bormann, N., Delsol, C., Dragani, R., Fuentes, M., Geer, A.J., Haimberger, L., Healy, S.B., Hersbach, H., Hólm, 
E.V., Isaksen, L., Kållberg, P., Köhler, M., Matricardi, M., McNally, A.P., Monge-Sanz, B.M., Morcrette, J-J., Park, B-K., Peubey, C., de Rosnay, P., Tavolato, C., Thépaut, J-N., and Vitart, F., 2011, The ERA-Interim reanalysis: configuration and performance of the data assimiliation system: Q.J.R. Meteorol. Soc., v. 137, p. 553-597.

Dodge, S., Bohrer, G., Weinzierl, R., Davidson, S.C., Kays, R., Douglas, D., Cruz, S., Han, J., Brandes, D., and Wikelski, M., 2013, The Environmental-Data Automated Track Annotation (Env-DATA) system-Linking animal tracks with environmental data: Movement Ecology, v. 1, no. 3.

Douglas, D.C., Weinzierl, R., Davidson, S.C., Kays, R., Wikelski, M., and Bohrer, G., 2012, Moderating Argos location errors in animal tracking data: Methods in Ecology and Evolution, v. 3, no. 6, p. 999-1007.

Duerr, A.E., Miller, T.A., Lanzone, M., Brandes, D., Cooper, J., O’Malley, K., Maisonneuve, C., Tremblay, J., and Katzner, T., 2012, Testing an emerging paradigm in migration ecology shows surprising differences in efficiency between flight modes: PLoS ONE, v. 7, no. 4, e35548, accessed December 9, 2015, at http://dx.doi.org/10.1371/journal.pone.0035548.

Kranstauber, B., Cameron, A., Weinzerl, R., Fountain, T., Tilak, S., Wikelski, M., and Kays, R., 2011, The Movebank data model for animal tracking: Environmental Modelling and Software, v. 26, no. 6, p. 834-835.

Lanzone, M.J., Miller, T.A., Turk, P., Brandes, D., Halverson, C., Maisonneuve, C., Tremblay, J., Cooper, J., O’Malley, K., Brooks, R.P., and Katzner, T., 2012, Flight responses by a migratory soaring raptor to changing meteorological conditions: Biology Letters, v. 8, p. 710-713, accessed December 9, 2015, at http://dx.doi.org/10.1098/rsbl.2012.0359.

Marks, P., 2014, Quantum positioning system steps in when GPS fails: New Scientist, no. 2969, accessed December 22, 2014, at https://www.newscientist.com/article/mg22229694-000-quantumpositioning-system-steps-in-when-gps-fails/.

Mendenhall, L., 2014, GPS data management manual: U.S. Fish and Wildlife Service, Revised for California Condor Recovery Partners, U.S. Fish and Wildlife Service, California Condor Recovery Program, $26 \mathrm{p}$.

Movebank, 2015, The Env-DATA system: accessed December 9, 2015, at https://www.movebank.org/node/6607.

PTCRB, 2015a, PTCRB - About us: accessed December 9, 2015, at https://www.ptcrb.com/index.cfm. PTCRB, 2015b, PTCRB certified devices: accessed December 9, 2015, at https://ptcrb.com/vendor/complete/complete_request.cfm?tab=Certified.

ScienceBase, 2015, Landscape Conservation Management and Analysis Portal Active Data, accessed December 10, 2015, at https://www.sciencebase.gov/lcmap/cacondor.

Tomkiewicz, S.M., Fuller, M.R., Kie, J.G., and Bates, K.K., 2010, Global positioning system and associated technologies in animal behaviour and ecological research: Philosophical Transactions of the Royal Society B, v. 365, p. 2163-2176, accessed December 9, 2015, at http://dx.doi.org/10.1098/rstb.2010.0090.

U.S. Fish and Wildlife Service, 2013, California condor (Gymnogyps californianus) 5-year reviewSummary and evaluation: Sacramento, Calif., Pacific Southwest Region, U.S. Fish and Wildlife Service, $64 \mathrm{p}$.

Xavier, G., and Dodge, S., 2014, An exploratory visualization tool for mapping the relationships between animal movement and the environment: Dallas/Fort Worth, Texas, MapInteract Conference Proceedings, 7 p., accessed December 9, 2015, at http://dx.doi.org/10.1145/2677068.2677071. 


\section{Appendix 1. Project Contributors Present at the December 17-18, 2013, Project Planning Meeting in Ventura, California.}

\section{Cellular Tracking Technologies, LLCTM:}

Andrew McGann - Product Specialist

Cellular Tracking Technologies, LLC

2405 North Center Avenue, Suite B

Somerset, Pennsylvania 15501

Phone: (814) 701-2511

Phone: (866) 582-8707 toll-free

Mobile: (717) 891-8145

FAX: (724) 550-2511

Email: andrew.mcgann@celltracktech.com

\section{U.S. Fish and Wildlife Service:}

Joseph Brandt - Supervisory Wildlife Biologist

Hopper Mountain - Bitter Creek NWF Complex

2493 Portola Road, Suite A

Ventura, CA 93003

Phone: 805-644-5185

Mobile: $805-827-1951$

FAX: 805-644-1732

Email: Joseph_brandt@fws.gov

Pat Lineback - Regional GIS Coordinator, Pacific Southwest Region

U.S. Fish and Wildlife Service

2800 Cottage Way, Room W-2606

Sacramento, CA 95825

Phone: 916-414-6559

Mobile: 916-765-3755

FAX: 916-414-6712

Email: Pat_lineback@fws.gov

Laura Mendenhall - Fish and Wildlife Biologist

McConnell Air Force Base

22 CES/CEIEC

57830 Pittsburgh Street, Suite 120

McConnell AFB, KS 67221

Phone: 316.759 .5765

Mobile: 913.481 .1022

Email: laura_mendenhall@,fws.gov 


\section{U.S. Geological Survey Alaska Science Center:}

David Douglas - Research Wildlife Biologist

USGS Alaska Science Center

250 Egan Drive

Juneau, AK 99801

Phone: 907-364-1576

FAX: 907-364-1540

Email: ddouglas@usgs.gov

\section{U.S. Geological Survey Fort Collins Science Center:}

Bob Waltermire - Leader, GIS and Remote Sensing Team

2150 Centre Avenue, Building C

Fort Collins, CO 80526

Phone: 970-226-9344

FAX: 970-226-9230

Email: waltermireb@usgs.gov

Christopher Emmerich - Software Developer

2150 Centre Avenue, Building C

Fort Collins, CO 80526

Phone: 970-226-9141

Mobile: 970-488-9775

Email: emmerichc@usgs.gov

\section{Movebank:}

Dr. Gil Bohrer - Assistant Professor of Ecological Engineering

The Ohio State University

417E Hitchcock Hall

2070 Neil Avenue,

Columbus, $\mathrm{OH} 43210$

Phone: 614-292-4178

Mobile: 919-699-6793

FAX: 614-292-3780

Email: Bohrer.17@osu.edu

Dr. Rolf Weinzierl

Max Planck Institute for Ornithology

Am Fuegsee 29, D-82418

Seehausen, Germany

Phone: +49 8841489870

Email: Rolf@strd.de 


\section{Appendix 2. Table of Specifications for Global Positioning System Transmitters Deployed on California Condors.}

Table 2-1. Specification for Global Positioning System Transmitters Deployed on California Condors.

[Specifications change rapidly as new technologies are incorporated into global positioning system transmitting devices. A new user should consult with the transmitter manufacturer for current specifications and capabilities. MTI, Microwave Telemetry, Inc. ${ }^{\text {TM}}$; PTT, Platform Transmitter Terminal; GSM, Global System for Mobile Communication; GPS, global positioning system; CTT, Cellular Tracking Technologies, LLCTM; HMNWR, Hopper Mountain National Wildlife Refuge; SiRF, SiRF Technology, Inc. ${ }^{\mathrm{TM}}$; WAAS, Wide Area Augmentation System; EGNOS, European Geostationary Navigation Overlay Service; N.A., not applicable; C, Centigrade; VDOP, vertical dilution of precision; HDOP, horizontal dilution of precision; CEP, circular error probable; \%, percent; RMS, root mean square; m, meters; s, seconds; LC, location class; VEP, vertical error probable; EGM96, Earth Gravitational Model 1996; CLS, Collecte Localisation Satellites; SiVTM, Satellite-in-View; KML, keyhole markup language; CSV, comma separated values; XML, extensible markup language; JSON, JavaScript Object Notation]

\begin{tabular}{|c|c|c|c|}
\hline \multirow{2}{*}{ Specifications } & \multicolumn{3}{|c|}{ GPS Transmitters } \\
\hline & MTI ARGOS/GPS PTT & MTI GSM/GPS & CTT GSM/GPS \\
\hline GPS Transmitter Type & $\begin{array}{c}\text { PTT-100 } 50 \text { gram solar patagial } \\
\text { Argos/GPS }\end{array}$ & $\begin{array}{c}50 \text { gram Patagial GPS Solar/GSM } \\
\text { 20-70 Transmitter }\end{array}$ & CTT-1050a-PM 2nd Generation \\
\hline Available Units (HMNWR Complex) & 32 & 10 & 17 \\
\hline Mount type & Patagial & Patagial & Patagial \\
\hline Antenna position & Straight out from back edge & Straight out from back edge & $\begin{array}{l}\text { Optimized for bird flying in } \\
\text { horizontal position }\end{array}$ \\
\hline Weight (grams) & 50 & 50 & 50 \\
\hline Power source & Solar & Solar & Solar \\
\hline GPS Receiver & $\begin{array}{c}\text { Internal sixteen channel micro } \\
\text { power GPS receiver }\end{array}$ & $\begin{array}{l}\text { Internal sixteen channel micro power } \\
\text { GPS receiver }\end{array}$ & $\begin{array}{c}48 \text { Channel L1 SiRF IV Chipset, } \\
\text { WAAS, EGNOS }\end{array}$ \\
\hline Alternate positioning mode & Doppler & N.A. & N.A. \\
\hline $\begin{array}{l}\text { Recommended Operational } \\
\text { Temperature }\end{array}$ & $-15 \mathrm{C}$ to $45 \mathrm{C}$ & $-15 \mathrm{C}$ to $45 \mathrm{C}$ & $-40 \mathrm{C}$ to $85 \mathrm{C}$ \\
\hline Day/night power conservation & $\begin{array}{l}\text { Microprocessor controlled } \\
\text { battery charge management to } \\
\text { allow the PTT to charge during } \\
\text { the day and collect data and } \\
\text { transmit at night }\end{array}$ & $\begin{array}{l}\text { Yes, and nighttime GPS fixes can be } \\
\text { taken and can be transmitted }\end{array}$ & $\begin{array}{c}\text { Yes, and nighttime GPS fixes } \\
\text { can be taken and can be } \\
\text { transmitted }\end{array}$ \\
\hline
\end{tabular}


Table 2-1. Specification for Global Positioning System Transmitters Deployed on California Condors.-Continued

[Specifications change rapidly as new technologies are incorporated into global positioning system transmitting devices. A new user should consult with the transmitter manufacturer for current specifications and capabilities. MTI, Microwave Telemetry, Inc. ${ }^{\text {TM}}$; PTT, Platform Transmitter Terminal; GSM, Global System for Mobile Communication; GPS, global positioning system; CTT, Cellular Tracking Technologies, LLCTM; HMNWR, Hopper Mountain National Wildlife Refuge; SiRF, SiRF Technology, Inc. ${ }^{\text {TM; }}$ WAAS, Wide Area Augmentation System; EGNOS, European Geostationary Navigation Overlay Service; N.A., not applicable; C, Centigrade; VDOP, vertical dilution of precision; HDOP, horizontal dilution of precision; CEP, circular error probable; \%, percent; RMS, root mean square; m, meters; s, seconds; LC, location class; VEP, vertical error probable; EGM96, Earth Gravitational Model 1996; CLS, Collecte Localisation Satellites; SiV TM, Satellite-in-View; KML, keyhole markup language; CSV, comma separated values; XML, extensible markup language; JSON, JavaScript Object Notation]

\begin{tabular}{|c|c|c|c|}
\hline \multirow{2}{*}{ Specifications } & \multicolumn{3}{|c|}{ GPS Transmitters } \\
\hline & MTI ARGOS/GPS PTT & MTI GSM/GPS & CTT GSM/GPS \\
\hline VDOP recorded & No & Yes & Yes \\
\hline HDOP recorded & No & Yes & Yes \\
\hline \multirow{2}{*}{ Horizontal accuracy - GPS } & ${ }^{1} \pm 2.5 \mathrm{~m}(\mathrm{CEP} 50 \%)$ & ${ }^{1} \pm 2.5 \mathrm{~m}(\mathrm{CEP} 50 \%)$ & ${ }^{1} \pm 2.5 \mathrm{~m}(\mathrm{CEP} 50 \%)$ \\
\hline & $\pm 18 \mathrm{~m}(\mathrm{CEP} 85 \%$ - verified $)$ & $\pm 18 \mathrm{~m}(\mathrm{CEP} 85 \%$ - verified $)$ & ${ }^{1} \pm 5$ meters $(2 \mathrm{dRMS} 95 \%)$ \\
\hline \multirow{4}{*}{ Horizontal accuracy - Doppler } & $<250 \mathrm{~m}(\mathrm{LC} 3)$ & \multirow{4}{*}{ N.A. } & \multirow{4}{*}{ N.A. } \\
\hline & $<500 \mathrm{~m}(\mathrm{LC} 2)$ & & \\
\hline & $<1500 \mathrm{~m}(\mathrm{LC} 1)$ & & \\
\hline & $>1500 \mathrm{~m}(\mathrm{LC} 0)$ & & \\
\hline \multirow{2}{*}{ Vertical accuracy - GPS } & \multirow{2}{*}{ \pm 22 meters } & \multirow{2}{*}{ \pm 22 meters } & ${ }^{1} \pm 4 \mathrm{~m}(\mathrm{VEP} 50 \%)$ \\
\hline & & & ${ }^{1} \pm 7.5 \mathrm{~m}(2 \mathrm{dRMS} 95 \%)$ \\
\hline Velocity and heading & Yes & Yes & $<0.01 \mathrm{~m} / \mathrm{s} ;<0.01^{\circ}$ \\
\hline Height format & Height above ellipsoid (m) & Height above ellipsoid (m) & $\begin{array}{l}\text { Height Above MSL } \\
\text { (EGM96 Geoid)(m) }\end{array}$ \\
\hline Other data recorded & $\begin{array}{c}\text { Date, Time, Speed, Heading, } \\
\text { Battery Voltage, Activity } \\
\text { Sensor Data, Temperature }\end{array}$ & $\begin{array}{c}\text { Date, Time, Location, Speed, Course, } \\
\text { Satellite Count, Battery Voltage, } \\
\text { Activity Sensor Data, Temperature }\end{array}$ & $\begin{array}{c}\text { Date, Time, Location, Speed, } \\
\text { Course, Tag Voltage }\end{array}$ \\
\hline Geofence & No & No & Yes \\
\hline Transmission type & Satellite/CLS America & GSM Network & $\begin{array}{c}\text { GSM Network: AT\& } \& T^{\mathrm{TM}} \text { and } \\
\text { T-Mobile }\end{array}$ \\
\hline
\end{tabular}


Table 2-1. Specification for Global Positioning System Transmitters Deployed on California Condors._Continued

[Specifications change rapidly as new technologies are incorporated into global positioning system transmitting devices. A new user should consult with the transmitter manufacturer for current specifications and capabilities. MTI, Microwave Telemetry, Inc. ${ }^{\text {TM}}$; PTT, Platform Transmitter Terminal; GSM, Global System for Mobile Communication; GPS, global positioning system; CTT, Cellular Tracking Technologies, LLCTM; HMNWR, Hopper Mountain National Wildlife Refuge; SiRF, SiRF Technology, Inc. ${ }^{\text {TM; }}$ WAAS, Wide Area Augmentation System; EGNOS, European Geostationary Navigation Overlay Service; N.A., not applicable; C, Centigrade; VDOP, vertical dilution of precision; HDOP, horizontal dilution of precision; CEP, circular error probable; \%, percent; RMS, root mean square; m, meters; s, seconds; LC, location class; VEP, vertical error probable; EGM96, Earth Gravitational Model 1996; CLS, Collecte Localisation Satellites; SiV TM, Satellite-in-View; KML, keyhole markup language; CSV, comma separated values; XML, extensible markup language; JSON, JavaScript Object Notation]

\begin{tabular}{|c|c|c|c|}
\hline \multirow{2}{*}{ Specifications } & \multicolumn{3}{|c|}{ GPS Transmitters } \\
\hline & MTI ARGOS/GPS PTT & MTI GSM/GPS & CTT GSM/GPS \\
\hline Transmission frequency & $\begin{array}{c}\text { Individual packets of data (3 } \\
\text { fixes per packet) transmitted } \\
\text { once per minute during } \mathrm{SiV}^{\mathrm{TM}} \\
\text { windows } \\
\end{array}$ & $\begin{array}{l}\text { 1/day; transmitter must be in cell } \\
\text { range during a 4-hour window }\end{array}$ & $\begin{array}{l}\text { 1/day if transmitter is located in } \\
\text { an area with GSM cellular } \\
\text { network coverage }\end{array}$ \\
\hline Transmission process & $\begin{array}{l}\text { Argos platforms transmit data to } \\
\text { satellites which transmit to } \\
\text { ground receiving stations. } \\
\text { Ground stations transfer data } \\
\text { to Argos Processing Centers } \\
\text { and from there to Movebank. }\end{array}$ & $\begin{array}{l}\text { Cellular modem connects to the } \\
\text { GSM network and data sent to } \\
\text { MT servers }\end{array}$ & $\begin{array}{c}\text { Cellular modem connects to the } \\
\text { GSM network and data sent to } \\
\text { CTT servers }\end{array}$ \\
\hline Transmit real-time & No & No & No \\
\hline Transmit window & $\begin{array}{l}\text { PTT transmits during } \mathrm{SiVTM} \\
\text { windows for a total of } \sim 8 \\
\text { hours/day; each satellite pass for } \\
\text { reception lasts } 10-14 \text { minutes }\end{array}$ & $\begin{array}{c}\text { 4-hour dynamic transmission window, } \\
\text { trying every hour with multiple } \\
\text { attempts if necessary }\end{array}$ & $\begin{array}{l}\text { Once a day. Retires every } \\
15 \text { minutes for } 75 \text { minutes } \\
\text { (reconfigurable). }\end{array}$ \\
\hline Data storage on-board & Yes & Yes & Yes \\
\hline Out of coverage area storage & 1 day of data & Up to 258,000 GPS fixes & $>100,000$ GPS fixes \\
\hline Data acquisition rate & $1 /$ hour & Dynamic $^{2}$ & Dynamic $^{2}$ \\
\hline Data dissemination & $\begin{array}{c}\text { Argos/CLS America through } \\
\text { Web; Telnet; Email }\end{array}$ & Email (Web portal soon) & CTT's Web User Interface \\
\hline Data file format & Text file and KML download & Text file and KML file & KML, CSV, XML, JSON \\
\hline Link to Movebank & Yes & Yes & Yes \\
\hline Change transmitter parameters remotely & No & Yes & Yes \\
\hline Operating lifetime & 3 years & 3 years & Unspecified \\
\hline Warranty period & 1 year & 1 year & 1 year \\
\hline
\end{tabular}




\section{Appendix 3. California Condor Management and Analysis Portal (CCMAP) (https://my.usgs.gov/ccmap)}

\section{California Condor Management and Analysis Portal (CCMAP)}

\section{(1) DISCLAIMER}

You are included on the email recipient list for the California Condor Daily Map and Alert emails because you have demonstrated a need to have access to California Condor GPS location data on a daily basis.

The U.S. Fish and Wildlife Service considers the data on the California Condor Daily Map and in the Alert emails sensitive.

Please refrain from forwarding the Map and Alert emails to anyone not on the email list, though you may share data within your organization.

If you have any questions about sharing data or discussing the contents of the Daily Map or Alert emails, please check with the U.S. Fish and Wildlife Service Hopper Mountain NWR Complex Office first.

\section{(2) NOTES ABOUT THE EMAIL}

If you would like to be removed from the email list, please notify the U.S. Fish and Wildlife Service Hopper Mountain NWR Complex Office.

\section{$\triangle \mathrm{KMZ}$}

You will receive two KMZ files showing one week's worth of unproofed GSM and Argos data for the Central and Southern California populations of California Condors at approximately 6:00 am PDT/PST from myusgs@usgs.gov.Please make any adjustments with spam filters so that this address is recognized.

You can choose to open both KMZ files in the same map or in one map at a time (recommended).

The KMZ files will vary in size--thus far, we have seen sizes from 2.2 to $3.2 \mathrm{MB}$.

\section{$\triangle A L E R T S$}

If a GPS unit has not moved in 24 hours, USGS will generate a separate alert email indicating the condor ID(s) and dates of "non-movement." You will receive this alert email until the dates of "non-movement" are outside of the last 7 days.
Alert emails are generated separatelyfor GSM and for Argos data and separatelyfor Southern California and Central California-managed condors. Only the condor field crews at each release site need to check alerts.

\section{(3) CONDOR RELEASE SITE FIELD CREWS ONLY}

Every time a new alert comes in, you can check to see if the "non-movement" has ended by viewing that bird's data under the "Individual birds" folder (see GOOGLE EARTH TABLE OF CONTENTS Section) and navigating down to the timestamps encapsulating the time of "nonmovement." If the bird has moved "normally" since, you can clear that alert from your conscience.

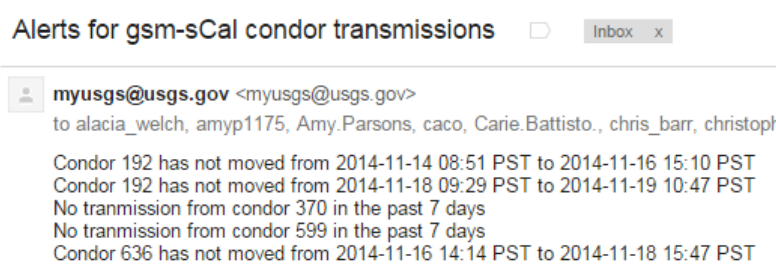

GPS units that have not transmitted in the past 7 days are of more concern. Field crew staff should check the sources of the data (CLS America, MTI emails, CTT user interface) first to make sure there is not an error in the data stream. Field crew staff should also check to make sure all Movebank deployments are up-to-date. If everything looks good, it is possible this GPS unit is malfunctioning or has fallen off or thebird has died.

\section{(4) HOW TO INTERPRET THE DATA \\ GOOGLE EARTH TABLE OF CONTENTS}

You should familiarize yourself with how to use Google Earth before looking at the daily map. Google has excellent help documentation here:

https://support.google.com/earth/?hl=en\#

The KMZ is set to open with "Day and Stationary" locations and paths for each condor checked under both the "gsm" and "argos" sub-folders. Click the small arrow next to either sub-folder and each sub-folder within to view all the options for viewing data. 


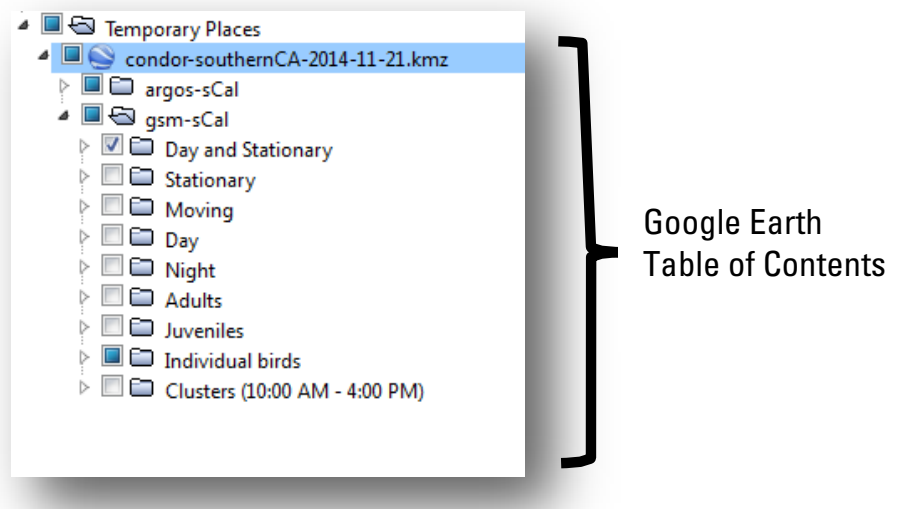

Within the sub-folders, try checking different options, e.g. "Night," "Juveniles" to filter the data.

Make sure you adjust the time slider bar in the upper left corner of your screen each time you select something in the table of contents (Google Earth defaults to narrowing the date range each time you adjust something in the table of contents). The time slider bar is in local time/date.

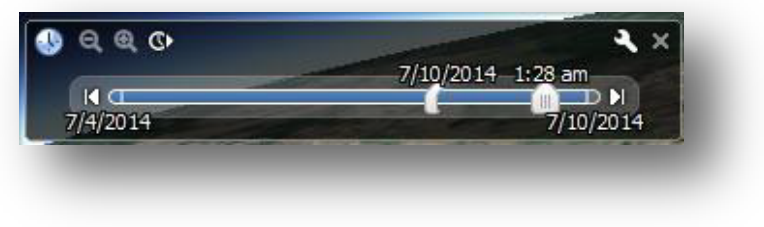

To view ALL GPS locations and paths for that week, you simply need to check "Individual birds" (so that a check mark appears--the blue shaded box means only some features within that sub-folder are checked; this is the default upon opening the map).

\section{-ATTRIBUTES}

You can click on any point, line, or cluster to access attributes.

To access point attributes, click on any point. Note the time and date are in the local time zone!

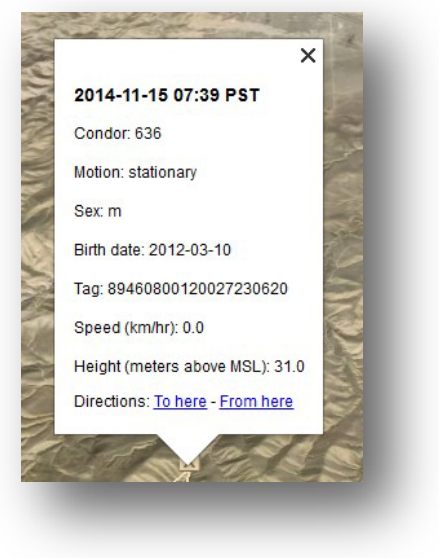

To access path attributes, click on any path segment.

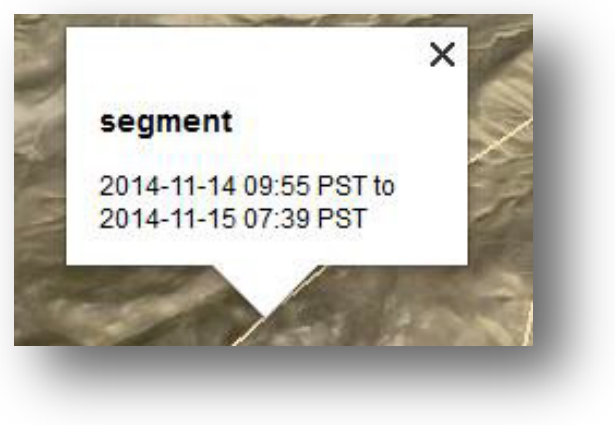

\section{$\rightarrow$ CLUSTERS}

When turned on, the "Clusters (10:00 AM - 4:00 PM)" option under each folder shows areas where $>1$ condors have been within 100 meters of each other with speeds less than or equal to 10 kilometers/hour between 10:00am and 4:00pm for the day before only (though the original cluster may have appeared a day or two before).

Clusters are portioned based on between group distance $>250$ meters. Yellow pushpins represent "non-persistent" clusters (< 3 days) and red pushpins represent "persistent" clusters ( $>=3$ of the past 4 days).

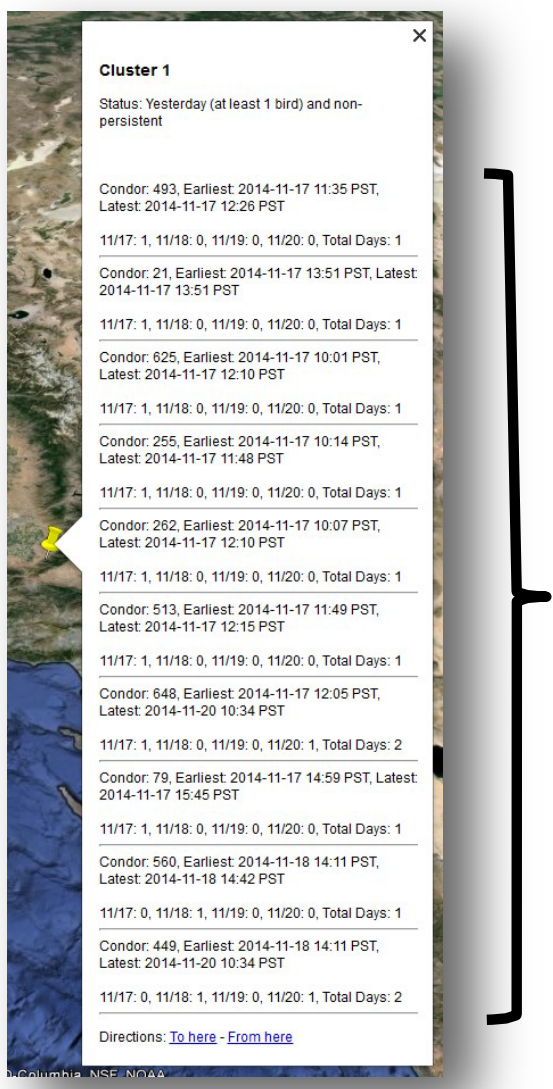

When you click on a cluster, a list of the condors associated with that cluster appears. Note: the status indication of "Yesterday (at least 1 bird)..." simply means at least 1 bird was still at the original cluster (which was defined by $>1$ bird at its inception) yesterday.

In general, clusters are proxies for potential feedings or habituation events. Only the condor field crews at each release site need to investigate or respond to clusters. 


\section{(5) FAQS}

(0) Why am I receiving so many alert emails?

(A) The alert algorithm is designed to flag periods of presumed non-movement as proxy for a dropped unit, mortality, malfunctioning unit, or injured condor. As a result, it will also flag periods when no data was collected (this happens sometimes with GSM units). That said, not every alert is indicative of something serious.

The responsibility to investigate these alerts falls on the release site field crews only.

(0) What should I do about these alerts? I am worried about these condors.

(A) It is the responsibility of the release site field crews on/yto investigate and respond to alerts. You are free to look at data from a bird on the alert list within the daily map, but rest assured the field crews will take care of alerts.

$* * * * * * * * * * * * * * * * * * * * * * * * * * * * * * * * * * * * * * * * * * *$

(0) Why are there so many GSM GPS

locations in the ocean/in other states?

(A) These are most likely 2D fixes and should be ignored. We see more 2D fixes from GSM units than Argos units simply because they are collecting more GPS data (e.g. 60 locations in an hour versus just one). If you believe a point in an otherwise "strange" area is not erroneous, check the timestamps on the points preceding and succeeding the point of interest. Could the bird have flown that far in that amount of time? You can also click on the path segments preceding and succeeding the point of interest.

$* * * * * * * * * * * * * * * * * * * * * * * * * * * * * * * * * * * * * * * * * * *$

(0) Does the path reflect actual flight path?

(A) No, the path is simply a line connecting consecutive points and as such reflects only the minimum distance between consecutive points.
(0) Why do some condors have more GPS locations than others?

(A) Different GPS units are programmed with different duty cycles. Argos GPS units collect GPS locations every hour during daylight. Microwave Telemetry GSM GPS units collect GPS locations up to every minute in peak daylight hours and every hour during the night. Cellular Tracking Technology GSM GPS units collect GPS locations every 15 minutes during daylight hours.

(0) Google Earth is moving very slowly, what should I do?

(A) Start by turning off all the Google Earth-provided Layers, e.g. "Borders and Labels", "Places", "Photos". Next, try checking and unchecking filter options and narrowing the time slider bar. It might work best for you to view data condor-by-condor under "Individual birds."

(0) Is this data suitable for analysis?

(A) No, this data is unproofed and therefore may contain GPS locations associated with dates in captivity and/or of poor quality.

$* * * * * * * * * * * * * * * * * * * * * * * * * * * * * * * * * * * * * * * * * * * *$

(0) I get an error message from Google Earth when I open the KMZ, it reads "This file is from a previous version of Google Earth or is not a Google Earth file" what should I do?

(A) You need to uninstall Google Earth and install the latest version. 


\section{Appendix 4. Long-Term Commitment by the Max Planck Institute for Ornithology to Operate Movebank}

[Reprinted with permission from Martin Wikelski, Director of the Max Planck Institute for Ornithology, April 11, 2016.]

\section{Max-Planck-Institut für Ornithologie \\ Max Planck Institute for Ornithology}

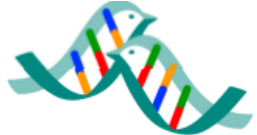

Vogelwarte Radolfzell · Dept. of Migration and Immuno-ecology · Am Obstberg 1 · D-78315 Radolfzell Chair of Ornithology · Universitätsstraße $10 \cdot$ D- 78464 Konstanz · Germany

To whom it may concern
Unlversltät Konstanz

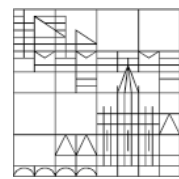

Martin Wikelski

Director/Professor

Tel.: +49 7732-1501-25

Fax: +49 (0) 7732-1501-69

wikelski@orn.mpg.de

www.uni-konstanz.de/wikelski/

\section{Re: Long-term committment to operate „Movebank “6}

November 2014

This is to confirm that we are committed to operate the global database 'Movebank' (www.movebank.org) on the long-term. This database was developed and is maintained by public funds. Its purpose is to serve humankind as an eternal repository of animal movement data across the planet, without any intention to serve particular individual interests or to create funds or benefits to any of the parties involved in its maintenance or upkeep.

To the best of our abilities, we guarantee that we will keep this publicly funded database available to its users in its current form, including

- Data storage and data format

- Privacy policy

- $\quad$ No costs

We are planning to enhance the features available in Movebank to better serve the internationally growing user base, including private, state, government and non-governmental entities. At no point will we hand out data to others except at the request of data owners. Users are expected to make their non-sensitive data public at a time when they consider this appropriate.

Sincerely

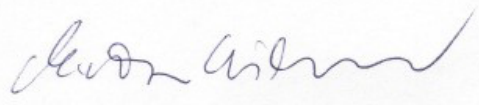

Martin Wikelski, Director, MPIO

Max-Planck-Institut für Ornithologie - Vogelwarte Radolfzell Am Obstberg 1. 78315 Radolfzell . Germany

Tel.:+49 (0) 7732-1501-0 - Fax: +49 (0) 7732-1501-69 - www.orn.mpg.de
Max-Planck-Institut für Ornithologic

Eberhard-Gwinner-Straße $\cdot 82319$ Seewiesen - Germany

Tel.: +49 (0) 8157-932-0 - Fax: +49 (0) 8157-932-400 - www.orn.mpg.de

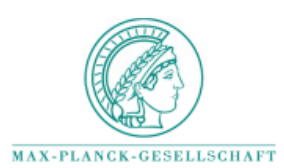

ISSN 2331-1258 (online) http://dx.doi.org/10.3133/ofr20161030 